\title{
Heating Augmentation Due to Compression Pad Cavities on the Project Orion CEV Heat Shield
}

\author{
Brian R. Hollis* \\ NASA Langley Research Center, Hampton, VA
}

\begin{abstract}
An experimental study has been conducted to assess the effects of compression pad cavities on the aeroheating environment of the Project Orion CEV heat-shield. Testing was conducted in Mach 6 and Mach 10 perfect-gas wind tunnels to obtain heating measurements in and around the compression pads cavities using global phosphor thermography. Data were obtained over a wide range of Reynolds numbers that produced laminar, transitional, and turbulent flow within and downstream of the cavities. The effects of cavity dimensions on boundary-layer transition and heating augmentation levels were studied. Correlations were developed for transition onset and for the average cavity-heating augmentation.
\end{abstract}

\section{Nomenclature}

$\begin{array}{ll}D & =\text { cavity diameter }(\mathrm{m}) \\ D / H & =\text { cavity aspect ratio } \\ h / h_{\mathrm{FR}} & =\text { ratio of measured-to-Fay-Riddell theory heating coefficients } \\ h / h_{\mathrm{SMOOTH}} & =\text { ratio of measured heating coefficients with and without cavity } \\ H & =\text { cavity depth }(\mathrm{m}) \\ H_{0} & =\text { total enthalpy }(\mathrm{J} / \mathrm{kg}) \\ H_{300 K} & =\text { cold-wall }(\text { at } 300 \mathrm{~K}) \text { enthalpy }(\mathrm{J} / \mathrm{kg}) \\ M_{\infty} & =\text { free stream Mach number } \\ M_{e} & =\text { boundary layer edge Mach number } \\ p_{\infty} & =\text { free stream pressure }(\mathrm{Pa}) \\ q_{\mathrm{FR}} & =\text { heat flux predicted using Fay-Riddell theory }\left(\mathrm{W} / \mathrm{cm}^{2}\right) \\ R & =\text { maximum vehicle radius }(\mathrm{m}) \\ R_{n} & =\text { nose }(\text { spherical cap) radius }(\mathrm{m}) \\ R_{T} & =\text { radius at tangency point of spherical cap and shoulder }(\mathrm{m}) \\ R_{S} & =\text { radius at aftbody shoulder }(\mathrm{m}) \\ R e_{\infty} & =\text { free stream unit Reynolds Number }(1 / \mathrm{m} \text { or } 1 / \mathrm{ft}) \\ T_{\infty} & =\text { free stream temperature }(\mathrm{K}) \\ U_{\infty} & =\text { free stream velocity }(\mathrm{m} / \mathrm{s}) \\ x & =\text { distance along vehicle symmetry (roll) axis }(\mathrm{m} \text { or in) } \\ y & =\text { distance in vehicle yaw-plane }(\mathrm{m} \text { or in) } \\ z & =\text { distance in vehicle pitch-plane }(\mathrm{m} \text { or in) } \\ \alpha & =\text { angle of attack }(\text { deg) } \\ \delta & =\text { boundary layer thickness }(\mathrm{m}) \\ \rho_{\infty} & =\text { free stream density }\left(\mathrm{kg} / \mathrm{m}^{3}\right) \\ \theta & =\text { boundary layer momentum thickness }(\mathrm{m}) \\ & \end{array}$

\section{Background}

The Crew Exploration Vehicle (CEV) concept was defined by NASA's Exploration Systems Architecture Study (Ref. 1). This study was conducted in 2005 to develop requirements for crew and cargo launch systems to support lunar and Mars exploration programs as well as for access to the International Space Station (ISS). Several versions of the Orion CEV are planned that will provide transportation first to the ISS, then to the moon, and finally to Mars.

The Crew Module of the CEV (Figure 1) has a configuration that is outwardly similar to the Apollo Command Module - a spherical-segment heat shield joined by a small toroidal section to a truncated-cone shaped crew compartment. The Orion CEV however, will be considerably larger than Apollo with a maximum heat shield diameter of $\sim 5 \mathrm{~m}$ (current configuration) vs. $3.912 \mathrm{~m}$ for Apollo. This larger size will allow transport of up to six crew members on International Space Station missions or up to 4 crew members on Lunar missions.

\footnotetext{
* Aerospace Engineer, Aerothermodynamics Branch, Senior AIAA Member
} 

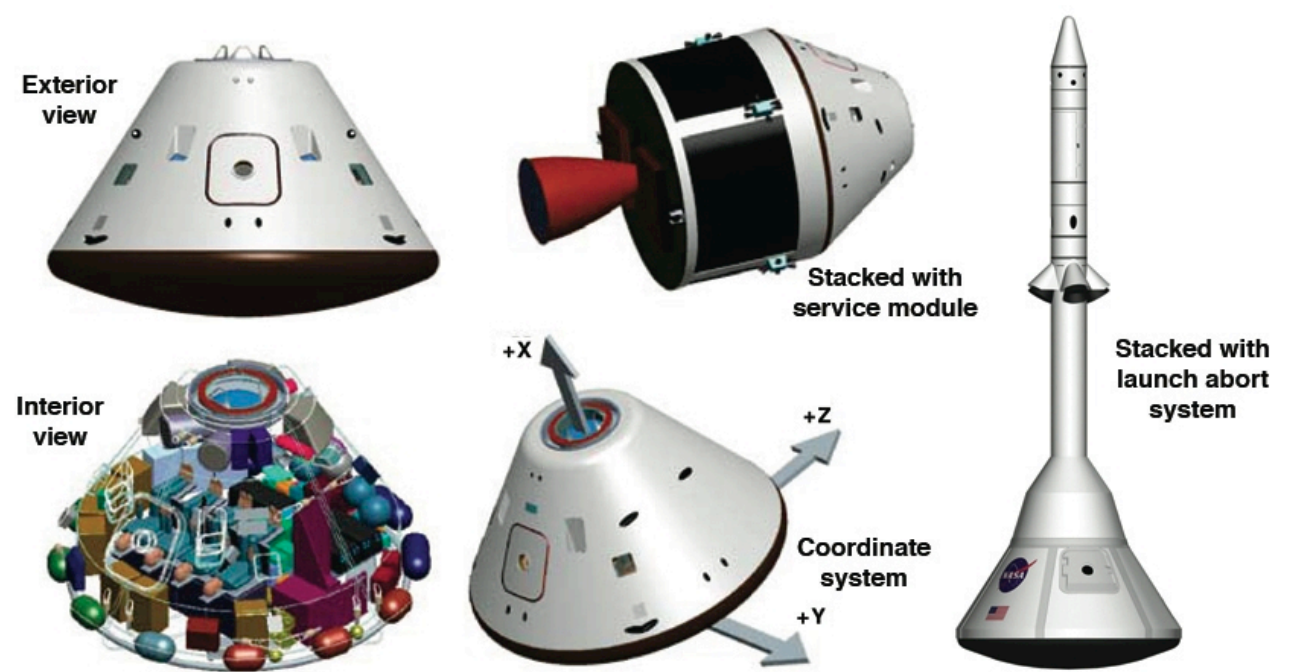

Figure 1. NASA Crew Exploration Vehicle (conceptual artwork)

In a proposed design similar to that of the Apollo program, the CEV crew module will be attached to the service module by six compression pad and tie-rod assemblies (Figure 2) spaced at 60-degree increments around the heatshield of the vehicle. Because the compression pads and the heat shield will be made from different materials, they will ablate at different rates during reentry and so at different points along the reentry trajectory the compression pads will be either recessed below, or protruding above the heat-shield. As evidenced from examination of recovered Apollo heat-shield (Figure 3) the compression pads, whether recessed or protruding, have the potential to cause large, albeit localized perturbations to heating levels as well as to promote boundary-layer transition.

In order to obtain information to support the design of the $\mathrm{CEV}$ heat shield, a parametric investigation of compression pad dimension effects on heating has been performed on a generic CEV design through testing in the Langley Research Center (LaRC) 20-Inch Mach 6 and 31-Inch Mach 10 Air Tunnels. In these tests, global heattransfer data on the pads and heat-shield were obtained using the Langley Thermographic Phosphor imaging technique. These tests supplement earlier efforts (Ref. 2) in which models with the same cavity diameter but with larger cavity depths (hence smaller aspect ratios, $D / H$ ) than were tested in this study. Additional data were also drawn from Ref. 3 in which various cavity sizes and configurations (including tension ties and annular attachment points) were tested. Supporting information was obtained through Computational Fluid Dynamics (CFD) predictions for "smooth-body" (no compression pads) performed at the wind tunnel test conditions to provide boundary-layer properties for use in correlation of the cavity transition and heating data.

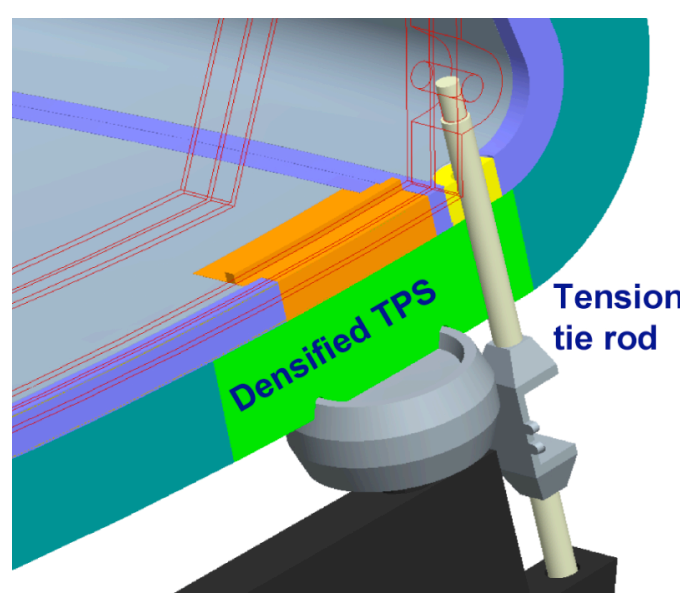

Figure 2. Generic compression pad / tie-rod assembly for CEV

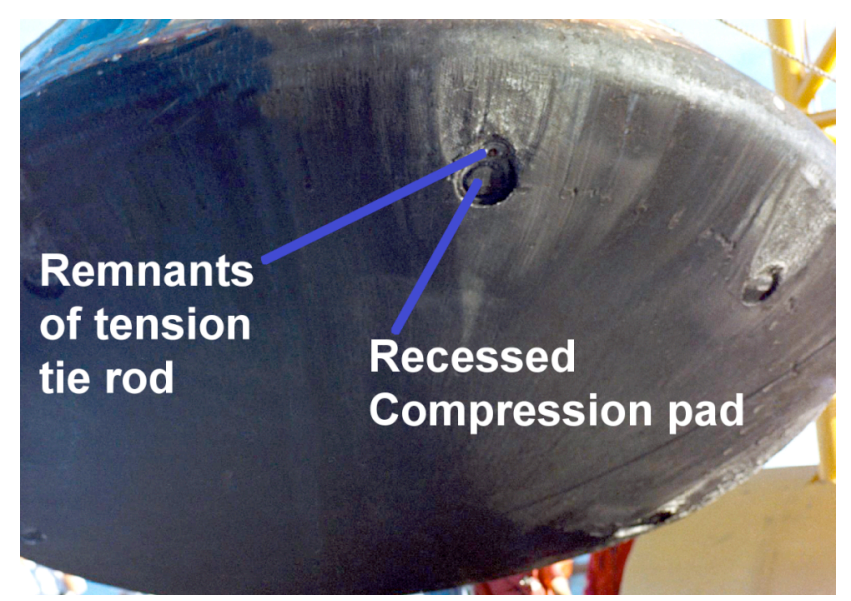

Figure 3. Effects of compression pad heating on Apollo Command Module heat shield 


\section{Experimental and Computational Methods}

\section{A. Compression Pad Wind Tunnel Model Design}

Wind tunnel models of the CEV vehicle with compression pad cavities were slip-cast in silica-ceramic and coated with a thermographic phosphor compound (Ref. 4). The model Outer Mold Line (OML) was a generic smooth-body representation based on early Project Orion design cycles (Figure 4). The model scale was 0.03556 (based on an assumed $5.00 \mathrm{~m}$ full scale at the time of the model design) that resulted in baseline 7-inch maxdiameter models, although an additional, larger 8 -inch diameter model was built to obtain naturally turbulent data. Compression pads were located on each model at 60-deg increments around the circumference of the heat-shield at a radial position of $81 \%$ of the maximum radius (Figure 5). The baseline pad diameter was 0.285 -in. on the model, which represented full-sized pads of 8.015-in. based on geometric scaling. Because the ablation/recession response of the pads and surrounding heat-shield are not yet defined and the compression pad design has not yet been finalized, models with cavity depths of 0.00625 -in. (C0-D1 model), 0.0125-in. (C1-D1 model), and 0.0250-in (C2D1 model) were fabricated. Cross-sectional views of these various cavity geometries are shown in Figure 6. Also shown in this figure is a larger 0.0500 -in. depth model (C3-D1 model) tested in the previous phase of the program (Ref. 2); note that the $1 \mathrm{X}$ and $2 \mathrm{X}$ model designations assigned in that test have been re-designated as $\mathrm{C} 2$-D1 and C3D1 for consistency with the current work. A final model (C1-D2) with a depth of 0.0125-in. but with half the nominal diameter $(0.1425$-in.) was also tested and is shown in this figure.

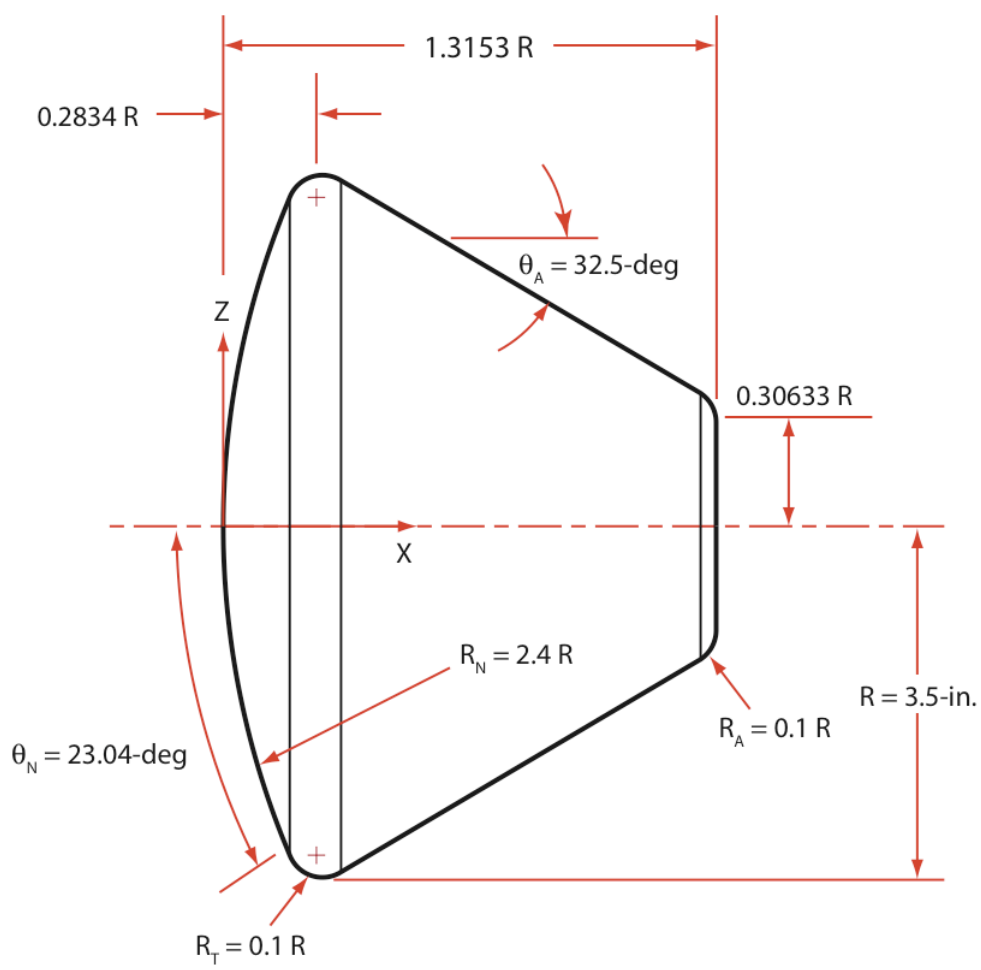

Figure 4. CEV wind tunnel model dimensions 


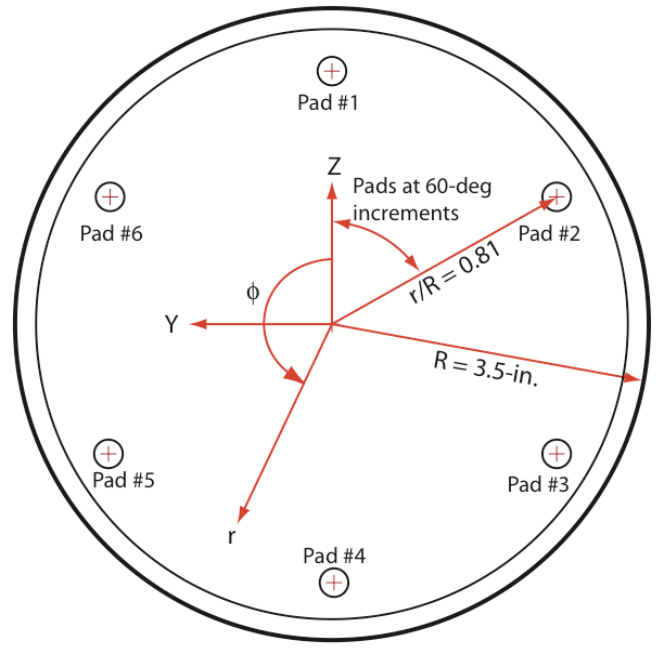

Figure 5. Compression pad cavity locations

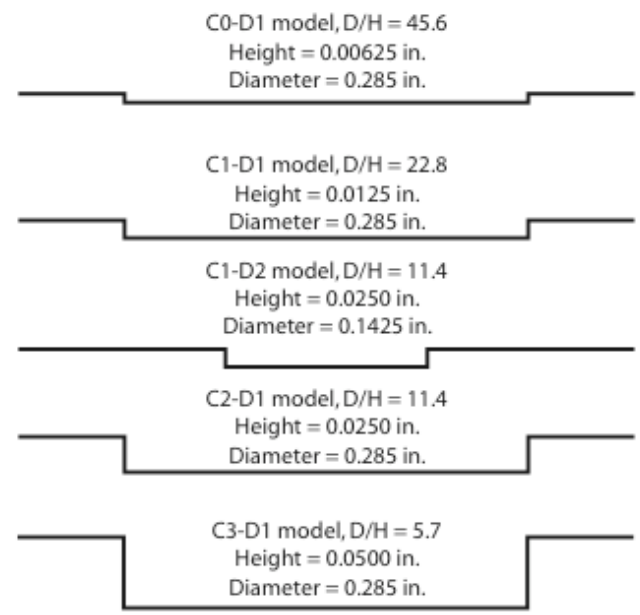

Figure 6. Compression pad cavity cross-sections

\section{B. Facility Descriptions and Test Parameters}

\section{NASA LaRC 31-Inch Mach 10 Air Tunnel}

The NASA LaRC 31-Inch Mach 10 Air Tunnel (Figure 7) is a conventional blow-down facility in which heated, dried, and filtered air is used as the test gas; a detailed description of this facility can be found in Ref. 5 . The tunnel has a two-dimensional, contoured nozzle that opens into a 31.0-in. by 31.0-in. test section. The tunnel is equipped with a side-mounted injection system that can transfer a model from the sheltered model box to the tunnel centerline in less than 1 second. Run times of several minutes are possible in this facility, although for aeroheating tests, run times of only a few seconds are required. The nominal reservoir conditions of this facility are stagnation pressures of $2.41 \mathrm{MPa}$ to $10.0 \mathrm{MPa}(350 \mathrm{psia}$ to $1450 \mathrm{psia})$ with a stagnation temperature of $1000 \mathrm{~K}\left(1800^{\circ} \mathrm{R}\right)$ that produce perfect-gas free stream conditions of Mach 9.7 to 10.0 at unit Reynolds numbers of $0.5 \times 10^{6} / \mathrm{ft}$ to $2.0 \times 10^{6} / \mathrm{ft}$ $\left(1.6 \times 10^{6} 1 / \mathrm{m}\right.$ to $\left.6.6 \times 10^{6} / \mathrm{m}\right)$.

CEV compression pad model heating data were obtained in the LaRC 31-Inch Mach 10 Air Tunnel during Test 456. Test parameters were: angles-of-attack $(\alpha)$ of 20-deg, 24-deg, and 28-deg; free-stream unit Reynolds numbers $\left(R e_{\infty}\right)$ of $0.5 \times 10^{6} / \mathrm{ft}$ to $1.2 \times 10^{6} / \mathrm{ft}$. Nominal conditions for each of the test Reynolds numbers are given in Table 1 ; run-to-run variations in conditions were less than $\pm 1 \%$. For all test conditions, laminar flow was produced upstream of all cavities. The Mach 10 test data obtained during this study on the C2-D1 model supercedes the C2-D1 data obtained during the previous (Ref. 2) Test 446 (under the old 1X model designation). This prior data-set is considered non-optimal because the model support system had not been designed for that tunnel and positioning of the model to obtain an acceptable viewing angle and sufficient illumination was difficult.

\section{NASA LaRC 20-Inch Mach 6 Air Tunnel}

The NASA Langley Research Center 20-Inch Mach 6 Air Tunnel (Figure 8) is a blow-down facility in which heated, dried, and filtered air is used as the test gas; a detailed description of this facility can be found in Ref. 5 . The tunnel has a two-dimensional contoured nozzle that opens into a $20.5 \mathrm{in} . \times 20.0$ in. $(0.52 \mathrm{~m} \times 0.508 \mathrm{~m})$ test section. The tunnel is equipped with a bottom-mounted injection system that can transfer a model from the sheltered model box to the tunnel centerline in less than $0.5 \mathrm{sec}$. Run times of up to 15 minutes are possible in this facility, although for the current aeroheating study, run times of only a few seconds were required. The nominal reservoir conditions of this facility produce perfect-gas free-stream flows with Mach numbers between 5.8 and 6.1 and unit Reynolds numbers of $0.5 \times 10^{6} / \mathrm{ft}$ to $7.3 \times 10^{6} / \mathrm{ft}\left(1.64 \times 10^{6} / \mathrm{m}\right.$ to $\left.23.3 \times 10^{6} / \mathrm{m}\right)$.

CEV compression pad model heating data were obtained in the LaRC 20-Inch Mach 6 Air Tunnel during Test 6954. Test parameters were: angle-of-attack $(\alpha)$ of 20 -deg; free-stream unit Reynolds numbers $\left(R e_{\infty}\right)$ of $1.0 \times 10^{6} / \mathrm{ft}$ to $6.9 \times 10^{6} / \mathrm{ft}$. Nominal conditions for each of the test Reynolds numbers are given in Table 2; run-to-run variations in conditions were less than $\pm 1 \%$. These conditions produced laminar flow upstream of the cavities for Reynolds numbers up to $5 \times 10^{6} / \mathrm{ft}$. At the $R e_{\infty}=6.9 \times 10^{6} / \mathrm{ft}$ condition, transitional flow was produced upstream from the three leeside cavities (pads \#6, \#1, and \#2). The C2-D1 and C3-D1 Mach 6 data from the previous Test 6946 (Ref. 2) compression pad study (then with $1 \mathrm{X}$ and $2 \mathrm{X}$ model designations) are also incorporated into the current analysis. 


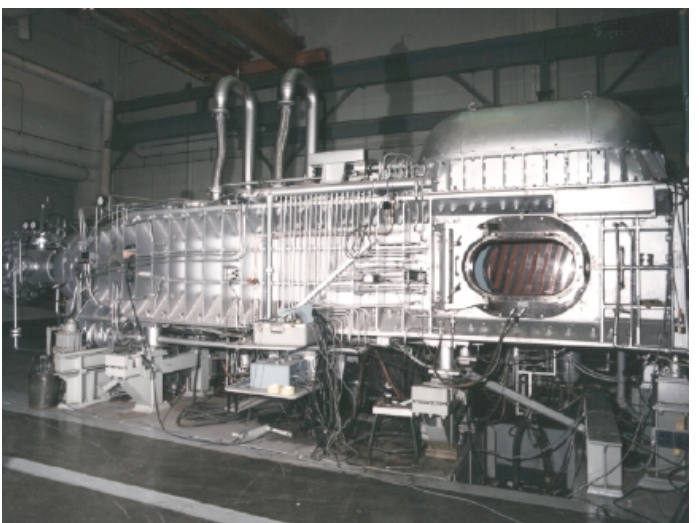

Figure 7. LaRC 31-Inch Mach 10 Air Tunnel

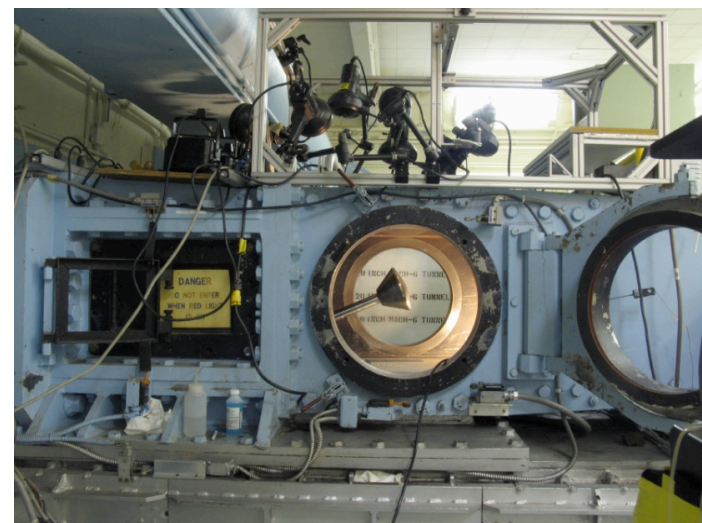

Figure 8. LaRC 20-Inch Mach 6 Air Tunnel

Table 1. Nominal Conditions for LaRC 31-Inch Mach 10 Air Tunnel Test 456

\begin{tabular}{ccccccccccc}
\hline $\begin{array}{c}\alpha \\
(\mathrm{deg})\end{array}$ & $\begin{array}{c}\mathrm{Re}_{\infty} \\
(1 / \mathrm{ft})\end{array}$ & $\begin{array}{c}\mathrm{Re}_{\infty} \\
(1 / \mathrm{m})\end{array}$ & $\mathrm{M}_{\infty}$ & $\begin{array}{c}\mathrm{P}_{\infty} \\
(\mathrm{Pa})\end{array}$ & $\begin{array}{c}\mathrm{T}_{\infty} \\
(\mathrm{K})\end{array}$ & $\begin{array}{c}\rho_{\infty} \\
\left(\mathrm{kg} / \mathrm{m}^{3}\right)\end{array}$ & $\begin{array}{c}\mathrm{U}_{\infty} \\
(\mathrm{m} / \mathrm{s})\end{array}$ & $\begin{array}{c}\mathrm{H}_{0}-\mathrm{H}_{300 \mathrm{~K}} \\
(\mathrm{~J} / \mathrm{kg})\end{array}$ & $\begin{array}{c}\mathrm{h}_{\mathrm{FR}} \\
\left(\mathrm{kg} / \mathrm{m}^{2} / \mathrm{s}\right)\end{array}$ & $\begin{array}{c}\mathrm{q}_{\mathrm{FR}} \\
\left(\mathrm{W} / \mathrm{cm}^{2}\right)\end{array}$ \\
\hline $20,24,28$ & $5.19 \mathrm{E}+05$ & $1.70 \mathrm{E}+06$ & 9.68 & 68.2 & 52.4 & $4.54 \mathrm{E}-03$ & 1404 & $7.38 \mathrm{E}+05$ & $6.41 \mathrm{E}-02$ & 4.73 \\
$20,24,28$ & $7.01 \mathrm{E}+05$ & $2.30 \mathrm{E}+06$ & 9.73 & 93.9 & 53.3 & $6.15 \mathrm{E}-03$ & 1424 & $7.66 \mathrm{E}+05$ & $7.58 \mathrm{E}-02$ & 5.80 \\
$20,24,28$ & $1.02 \mathrm{E}+06$ & $3.34 \mathrm{E}+06$ & 9.81 & 130.1 & 51.9 & $8.74 \mathrm{E}-03$ & 1415 & $7.53 \mathrm{E}+05$ & $8.97 \mathrm{E}-02$ & 6.75 \\
$20,24,28$ & $1.22 \mathrm{E}+06$ & $4.00 \mathrm{E}+06$ & 9.84 & 159.0 & 52.7 & $1.05 \mathrm{E}-02$ & 1431 & $7.77 \mathrm{E}+05$ & $9.98 \mathrm{E}-02$ & 7.74 \\
\hline
\end{tabular}

Table 2. Nominal Conditions for LaRC 20-Inch Mach 6 Air Tunnel Tests 6946 and 6954

\begin{tabular}{ccccccccccc}
\hline $\begin{array}{c}\alpha \\
(\mathrm{deg})\end{array}$ & $\begin{array}{c}\mathrm{Re}_{\infty} \\
(1 / \mathrm{ft})\end{array}$ & $\begin{array}{c}\mathrm{Re}_{\infty} \\
(1 / \mathrm{m})\end{array}$ & $\mathrm{M}_{\infty}$ & $\begin{array}{c}\mathrm{P}_{\infty} \\
(\mathrm{Pa})\end{array}$ & $\begin{array}{c}\mathrm{T}_{\infty} \\
(\mathrm{K})\end{array}$ & $\begin{array}{c}\rho_{\infty} \\
\left(\mathrm{kg} / \mathrm{m}^{3}\right)\end{array}$ & $\begin{array}{c}\mathrm{U}_{\infty} \\
(\mathrm{m} / \mathrm{s})\end{array}$ & $\begin{array}{c}\mathrm{H}_{0}-\mathrm{H}_{300 K} \\
(\mathrm{~J} / \mathrm{kg})\end{array}$ & $\begin{array}{c}\mathrm{h}_{\mathrm{FR}} \\
\left(\mathrm{kg} / \mathrm{m}^{2} / \mathrm{s}\right)\end{array}$ & $\begin{array}{c}\mathrm{q}_{\mathrm{FR}} \\
\left(\mathrm{W} / \mathrm{cm}^{2}\right)\end{array}$ \\
\hline 24 & $1.07 \mathrm{E}+06$ & $3.51 \mathrm{E}+06$ & 5.89 & 295.3 & 61.5 & $1.67 \mathrm{E}-02$ & 926 & $1.90 \mathrm{E}+05$ & $7.48 \mathrm{E}-02$ & 1.42 \\
24 & $2.08 \mathrm{E}+06$ & $6.83 \mathrm{E}+06$ & 5.96 & 576.3 & 62.2 & $3.23 \mathrm{E}-02$ & 942 & $2.05 \mathrm{E}+05$ & $1.06 \mathrm{E}-01$ & 2.18 \\
24 & $2.94 \mathrm{E}+06$ & $9.63 \mathrm{E}+06$ & 5.99 & 803.0 & 61.8 & $4.53 \mathrm{E}-02$ & 943 & $2.06 \mathrm{E}+05$ & $1.26 \mathrm{E}-01$ & 2.58 \\
24 & $4.05 \mathrm{E}+06$ & $1.33 \mathrm{E}+07$ & 6.01 & 1101.0 & 61.7 & $6.23 \mathrm{E}-02$ & 844 & $2.07 \mathrm{E}+05$ & $1.48 \mathrm{E}-01$ & 3.05 \\
24 & $5.04 \mathrm{E}+06$ & $1.65 \mathrm{E}+07$ & 6.02 & 1415.1 & 63.1 & $7.83 \mathrm{E}-02$ & 957 & $2.21 \mathrm{E}+05$ & $1.68 \mathrm{E}-01$ & 3.71 \\
24 & $6.91 \mathrm{E}+06$ & $2.27 \mathrm{E}+07$ & 6.04 & 1928.7 & 63.0 & $1.07 \mathrm{E}-01$ & 958 & $2.21 \mathrm{E}+05$ & $1.97 \mathrm{E}-01$ & 4.36 \\
24 & $7.46 \mathrm{E}+06$ & $2.45 \mathrm{E}+07$ & 6.04 & 2058.0 & 62.5 & $1.15 \mathrm{E}-01$ & 954 & $2.17 \mathrm{E}+05$ & $2.03 \mathrm{E}-1$ & 4.40 \\
\hline
\end{tabular}

\section{Data Acquisition, Reduction, Mapping, and Uncertainties}

\section{Data Acquisition and Reduction}

Heating levels over the model were measured using the two-color, relative-intensity, global thermographic phosphor method (Refs. 6, 7). In this method, heat-transfer coefficients are determined by assuming a step-function in heat-transfer beginning at injection of the model into the tunnel, which corresponds to a parabolic temperaturetime history. The model is illuminated by ultra-violet light sources that produce temperature-dependent fluorescence of the phosphor-coating and images of the model are taken in the tunnel before and during a run using a three-color, charge-coupled device camera. The IHEAT (Imaging for Hypersonic Experimental Aerothermodynamic Testing) code uses calibrations to convert the intensity data from each image pixel to temperatures and then performs the heat-transfer computations. Heat-transfer distributions from IHEAT are expressed in terms of the ratio $h / h_{\mathrm{FR}}$, where $h_{\mathrm{FR}}$ is the heat-transfer coefficient resulting from a Fay-Riddell computation (Ref. 8) for the heat-transfer to a sphere with the radius-of-curvature of the CEV heat-shield (8.4 in. / $0.21336 \mathrm{~m}$ ) at a wall temperature of $300 \mathrm{~K}$.

\section{Data Mapping}

The image data obtained from IHEAT were corrected for optical perspective effects and mapped to a threedimensional (3-D) surface model of the CEV geometry with compression pads. To accomplish this mapping,

5

American Institute of Aeronautics and Astronautics 
perspective transformations are first performed on the 3-D surface geometry until its 2-D projection matches that of the 2-D image data. The image data are then assigned transformed $(x, y, z)$ coordinates based on interpolation between the image and surface geometry, and then the transformation is inverted to obtain a corrected 3-D heating distribution. One refinement to this process has been made since its original use in the earlier compression pad test (Ref. 2). Instead of interpolating an $(x, y, z)$ coordinate onto each image pixel, the image pixel heating data are instead interpolated onto each $(x, y, z)$ of the surface geometry. While this method introduces some additional error into the interpolation of the image data, which is of much lower resolution than the surface geometry, the final result does not produce jagged edge at the bounds of the image domain and also retains the exact representation of the compression pad geometry. The difference between these two methods can be seen by comparing Figure 9 and Figure 10.

After mapping the image data to the 3-D surface geometry, further information can be obtained by extracting heating distributions along specific line-cut stations. Data were extracted along the pitch-symmetry plane (i.e. the centerline) and along line cuts through the center of each pad that were roughly aligned with the near-surface streamlines at $\alpha=24-\mathrm{deg}$. These compression pad data-cut locations are shown in Figure 11.

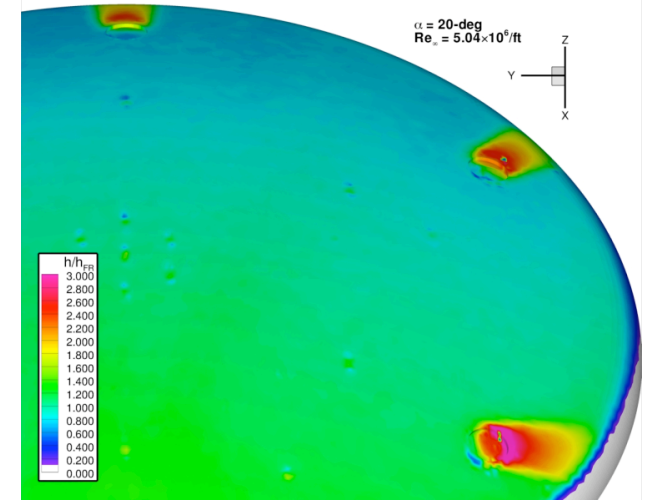

Figure 9. Sample 3-D mapped image data, using interpolation of image pixels to surface geometry

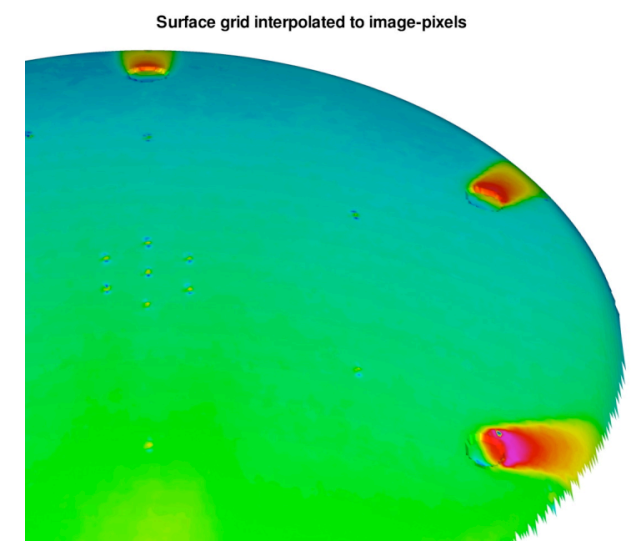

Figure 10. Sample 3-D mapped image data, using interpolation of surface geometry to image pixels

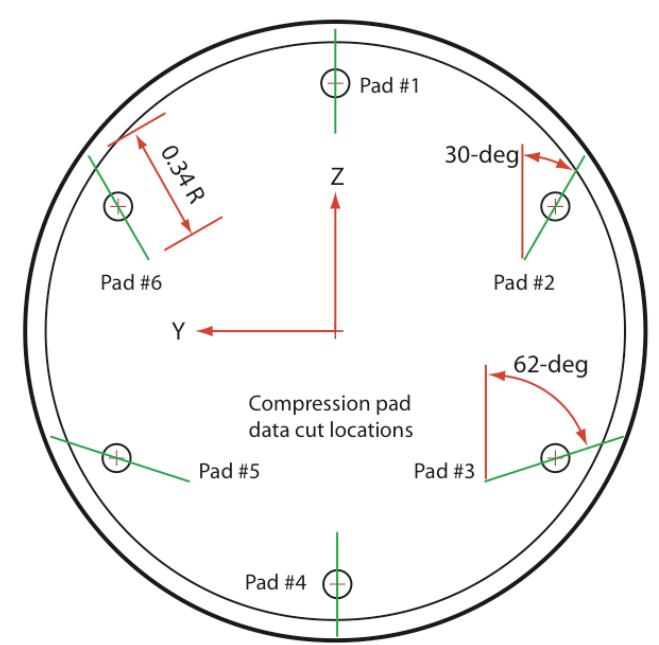

Figure 11. Compression pad data-cut locations

\section{Data Uncertainties}

For testing of a blunt-body configuration such as the CEV, an uncertainty estimate for the measurement technique of approximately $\pm 10 \%$ can be made based on Ref. 7 . Additional uncertainties are introduced through the mapping and processing of the data. Uncertainties also are introduced through the variation of wind-tunnel flow conditions. Since the repeatability of flow conditions is very good, the resulting uncertainty in heating measurements was estimated to be only on the order of $\pm 5 \%$. The other major source of uncertainty which must be considered is the mapping of pixel values from the image data to physical coordinates. This uncertainty is highly problem dependent; on the overall acreage of a CEV model this uncertainty is estimated to be on the order of $\pm 10 \%$. However, in geometrically-complex regions, such as within/around the compression pads or at the heat-shield shoulder, where the scale of such a feature approaches the resolution of the camera optics, this uncertainty could be much higher. For instance, the localized heating spike observed downstream of a recessed pad's cavity or on the leading edge of a protruding pad may be resolved to only a few image pixels and the resulting geometric uncertainty could be on the order of $\pm 25 \%$ to $\pm 50 \%$. In the current analysis, the quoted uncertainty for the smooth OML was determined from a root-mean-square summation of that from the acquisition uncertainty $( \pm 10 \%)$, flow conditions $( \pm 5 \%)$, and the acreage estimate for image mapping $( \pm 10 \%)$, which resulted in an overall experimental uncertainty of $\pm 15 \%$. For the heating data in and immediately 
around the compression pads, the nominal mapping error was set to $\pm 25 \%$ which resulted in the overall pad-region uncertainty increasing to $\pm 27 \%$.

\section{Computational Method}

Flow field predictions were performed using the LAURA (Langley Aerothermodynamic Upwind Relaxation Algorithm) code (Refs. 9 - 10) to obtain boundary-layer properties for use in correlating the experimental data. LAURA is a three-dimensional, finite-volume solver that includes perfect-gas, equilibrium, and non-equilibrium chemistry models. In this study, the perfect-gas air model was used for the wind tunnel predictions. Free-stream conditions in the LaRC wind tunnels did not vary significantly from run to run, so the nominal conditions in Table 1 and Table 2 were used, with the wall temperature set to a constant $300 \mathrm{~K}$. The use of a constant wall temperature was acceptable because the heat-transfer coefficient varies only slightly over the range of wall temperatures produced in these facilities. Solutions were performed at all wind tunnel test conditions on a smooth-OML (no compression pad cavities) grid. The smooth-OML cases were performed using the laminar, thin-layer NavierStokes formulation. This methodology has been shown to produce good comparisons with experimental data in previous CEV studies; e. g. Refs. 11 - 13.

\section{Results and Analysis}

\section{A. Global Effects on Heating}

Sample 3-D mapped, global heating images obtained from the Mach 10 and Mach 6 tunnel tests are shown in Figure 12 in terms of $h / h_{\mathrm{FR}}$. These data are for the C1-D1 model and the images are arranged in order of increasing free stream Reynolds numbers. Data similar in character but of different heating levels were obtained for the other model configurations, although all models were not tested at all Mach 6 and Mach 10 Reynolds numbers.

In these images it can be seen that the flow approaching the cavities was laminar at all test conditions except at the highest Mach 6 test Reynolds number $\left(\operatorname{Re}_{\infty}=6.9 \times 10^{6} / \mathrm{ft}\right)$ where transitional flow occurred upstream of the three leeside cavities. In all cases, the compression pad cavities perturbed the incoming flow which led to increased heating downstream of the cavities. For the three lowest Reynolds numbers (all of which are Mach 10 cases), there appeared to be little change in the magnitude of augmented heating downstream of the pads, which indicated that the flow remained laminar; for these three cases, the heating on the cavity floor was also noticeably lower than that upstream of the pad. For $\operatorname{Re}_{\infty} \geq 1.22 \times 10^{6} / \mathrm{ft}$, the three leeside pads (\#1, \#2, and \#6 at 0 -deg and $\pm 60-\mathrm{deg}$ ) experienced increasing downstream heating with Reynolds numbers which indicated progression of the boundarylayer state at the pad from transitional to turbulent flow. For the $\# 3$ and $\# 5$ pads (at \pm 120 -deg) similar behavior was observed but with transition onset appearing first at the Mach $6, \mathrm{Re}_{\infty}=2.08 \times 10^{6} / \mathrm{ft}$ condition. Local Reynolds numbers at the $\# 4$ pad (near the stagnation region) remained very low and transition onset was not observed until the highest Mach 6 Reynolds number condition of $\mathrm{Re}_{\infty}=6.91 \times 10^{6} / \mathrm{ft}$.

\section{B. Detailed Cavity Heating Distributions}

Heating distributions extracted from the image data in Figure 12 along the line cuts through each pad are shown in Figure 13. For each pad, the data from all test Reynolds numbers are plotted vs. $z / R$ for pad \#1, \#2, \#4, and \#6 or, to better reflect the orientation of the line cut, vs. $y / R$ for pads $\# 3$ and $\# 5$. The upstream $h / h_{\mathrm{FR}}$ distributions were nearly constant for all Reynolds numbers except at $\mathrm{Re}_{\infty}=6.91 \times 10^{6} / \mathrm{ft}$, which provided evidence that the flow incoming to the pads was laminar for all conditions except at this highest Reynolds number where it was transitional upstream of pads $\# 1, \# 2$, and $\# 6$. Within the compression pad cavities, the $h / h_{\mathrm{FR}}$ distributions also remained relatively constant at the three lowest Reynolds numbers, again indicating laminar flow. At $\operatorname{Re}_{\infty} \geq 1.22 \times 10^{6} / \mathrm{ft}$ (depending on the pad location), the $h / h_{\mathrm{FR}}$ distributions began to increase with Reynolds number as is characteristic of transitional or turbulent flow. For all cases, the highest heating levels were produced around the downstream wall and lip of each cavity, which essentially represents a forward facing step.

\section{Cavity Heating Augmentation}

In the design of the CEV flight vehicle, the heating augmentation above smooth-OML levels in and around the compression pad cavities is of interest; this quantity will be referred to as $h / h_{\mathrm{SMOOTH}}$. To determine this ratio, a smooth-OML reference heating value, $\left(h / h_{\mathrm{FR}}\right)_{\mathrm{SMOOTH}}$, was first determined for each pad at each test condition by averaging the measured heating levels over a small region upstream of the respective pad. The augmentation factor $h / h_{\text {SMOотн }}$ was then computed by dividing the measured $h / h_{\mathrm{FR}}$ values around each pad by the reference $\left(h / h_{\mathrm{FR}}\right)_{\mathrm{SMOOTH}}$ for that pad. The heating data from Figure 12 is shown recast in terms of $h / h_{\mathrm{SMоOтH}}$ in Figure 14. 

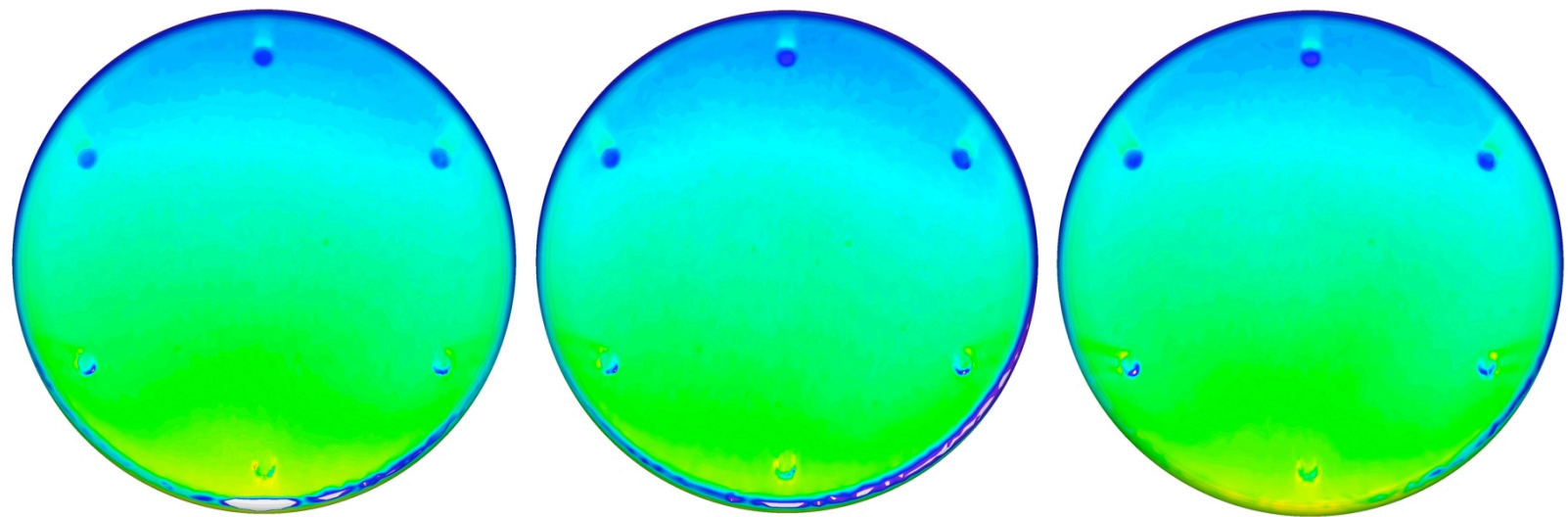

$M_{\infty}=10, \operatorname{Re}_{\infty}=0.52 \times 10^{6} / \mathrm{ft}$

$$
M_{\infty}=10, \operatorname{Re}_{\infty}=0.70 \times 10^{6} / \mathrm{ft}
$$
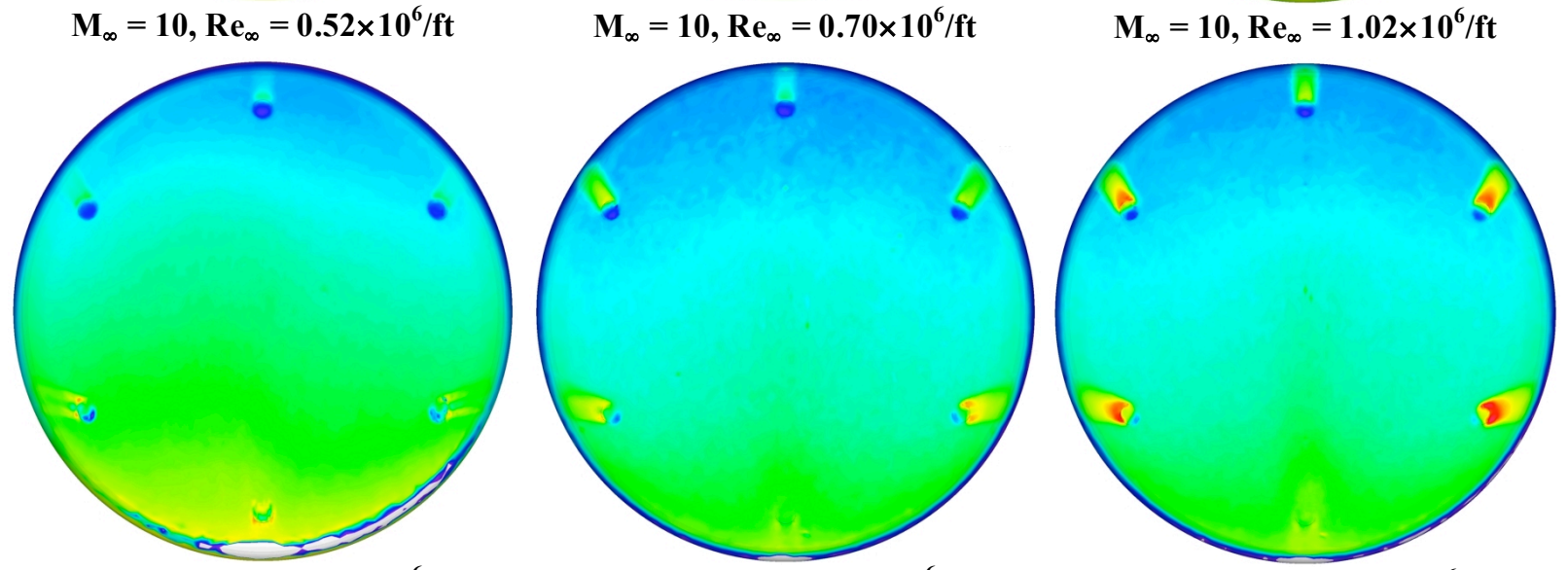

$$
M_{\infty}=10, \operatorname{Re}_{\infty}=1.22 \times 10^{6} / \mathrm{ft}
$$

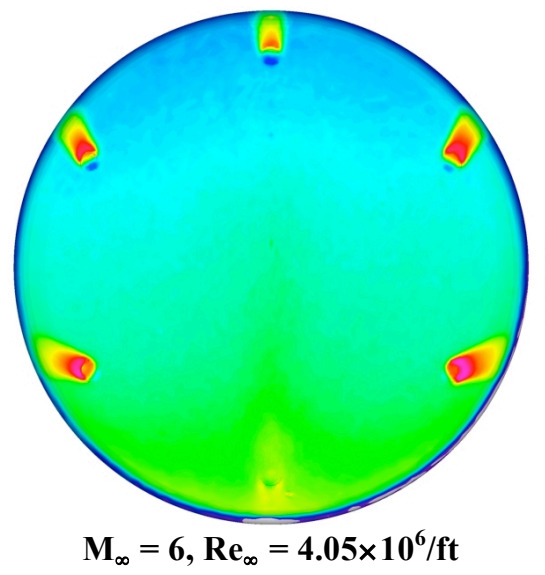

$$
M_{\infty}=6, \operatorname{Re}_{\infty}=2.08 \times 10^{6} / \mathrm{ft}
$$

$$
M_{\infty}=6, \operatorname{Re}_{\infty}=2.94 \times 10^{6} / \mathrm{ft}
$$
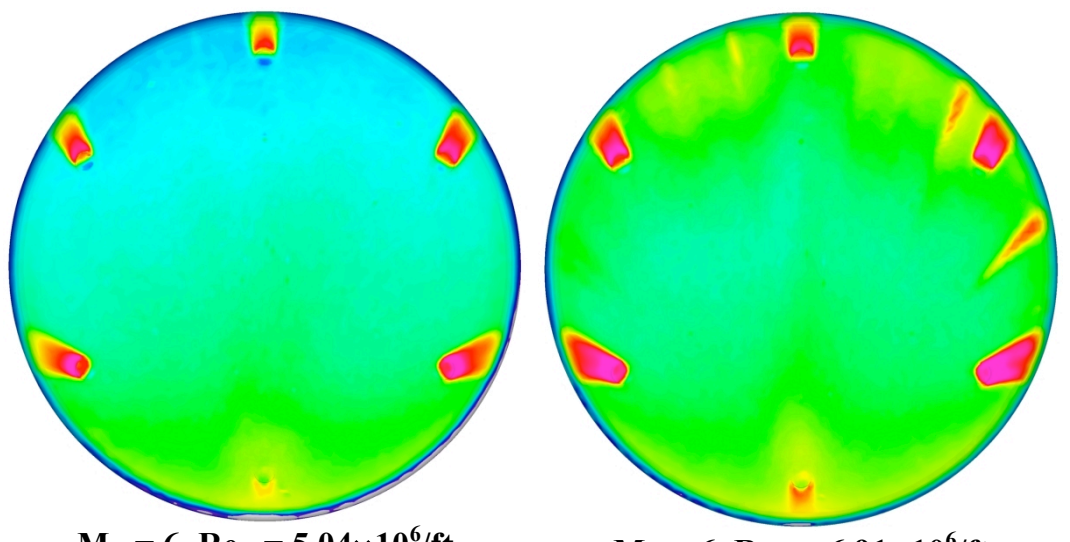

$$
M_{\infty}=6, \operatorname{Re}_{\infty}=5.04 \times 10^{6} / \mathrm{ft}
$$$$
M_{\infty}=6, \operatorname{Re}_{\infty}=6.91 \times 10^{6} / \mathrm{ft}
$$

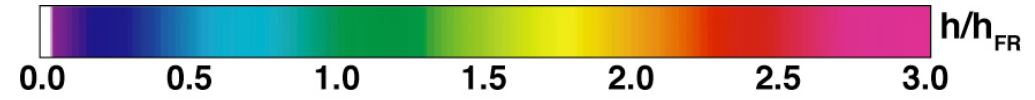

Figure 12. Global heating distributions measured on C1-D1 model, $\alpha=24-\mathrm{deg}$ 

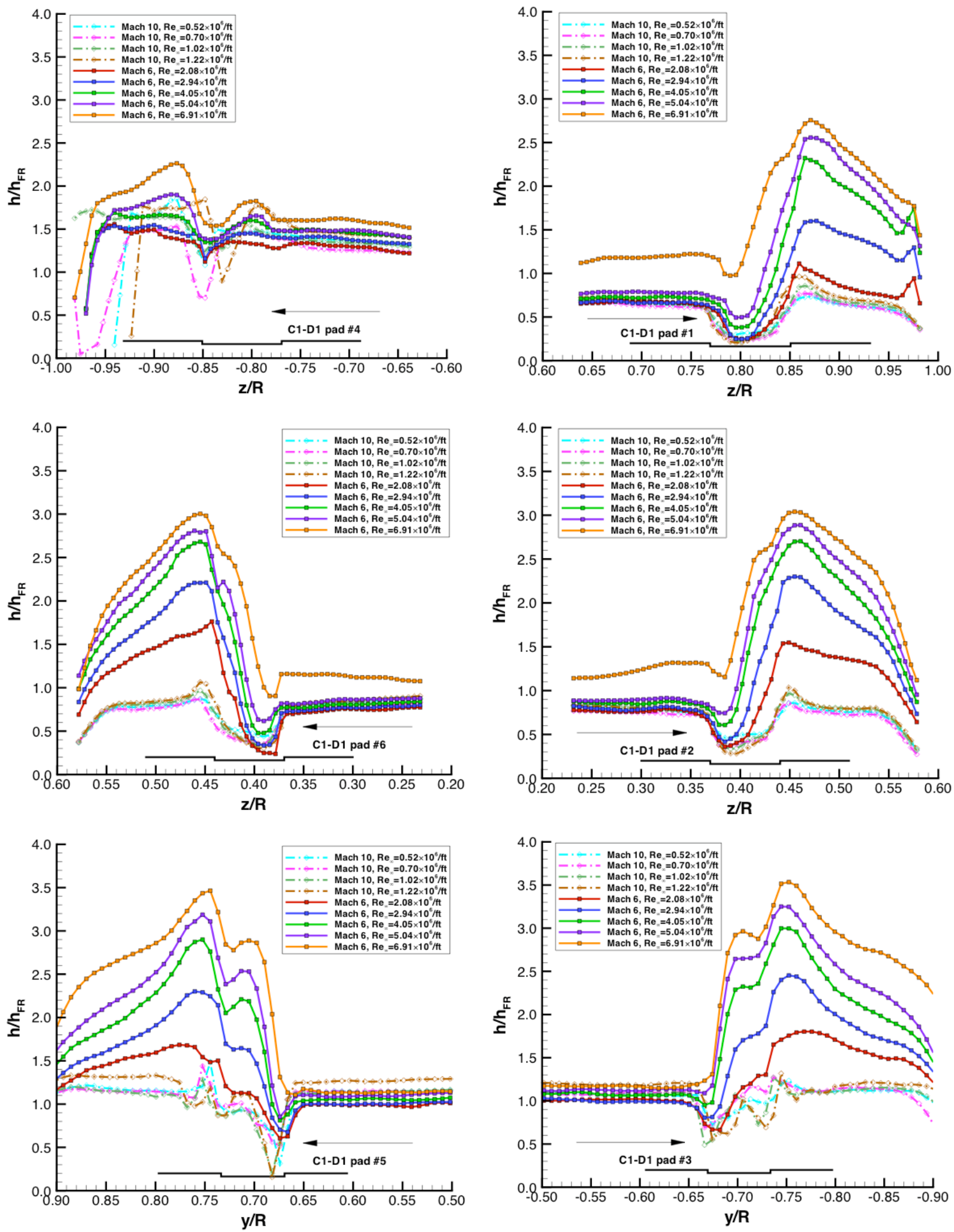

Figure 13. Heating distributions through C1-D1 model pad centers, $\alpha=24$-deg

American Institute of Aeronautics and Astronautics 

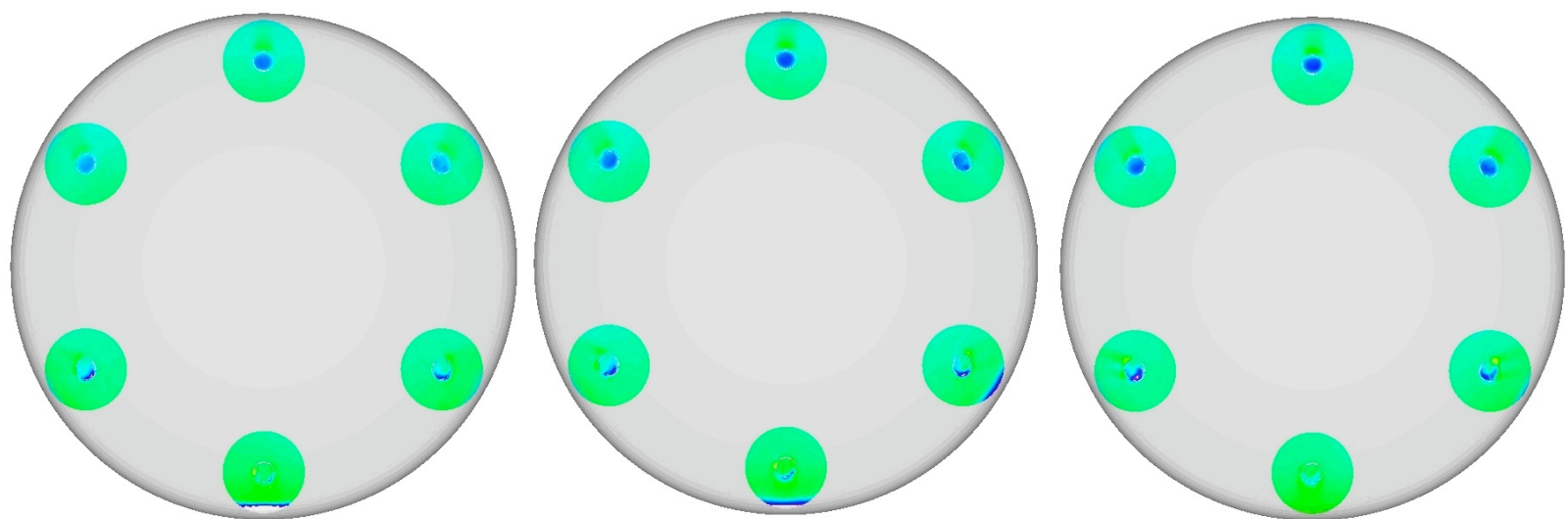

$M_{\infty}=10, \operatorname{Re}_{\infty}=0.52 \times 10^{6} / \mathrm{ft}$

$M_{\infty}=10, \operatorname{Re}_{\infty}=0.70 \times 10^{6} / \mathrm{ft}$
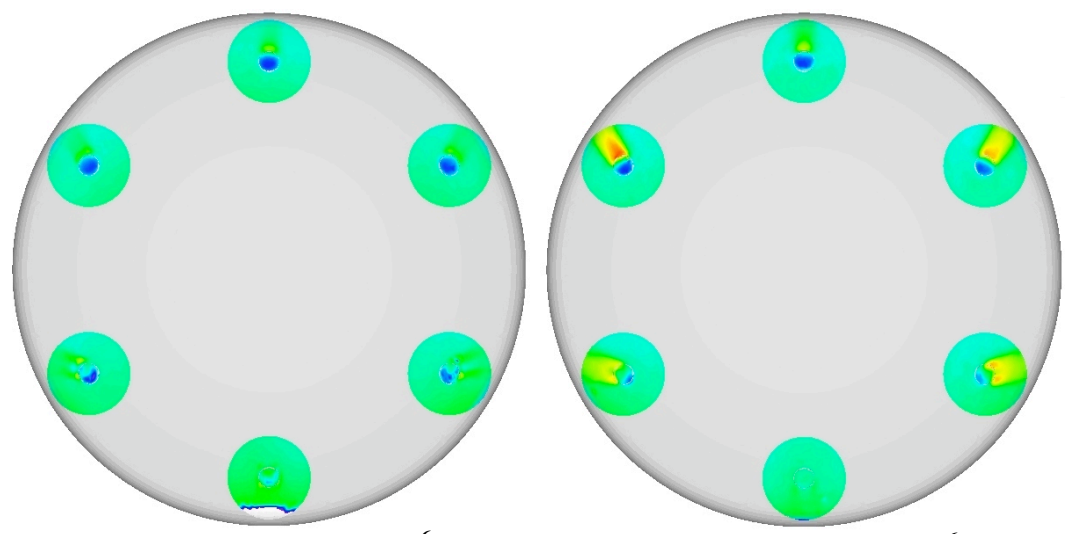

$M_{\infty}=10, \operatorname{Re}_{\infty}=1.02 \times 10^{6} / \mathrm{ft}$

$M_{\infty}=10, \operatorname{Re}_{\infty}=1.22 \times 10^{6} / \mathrm{ft}$

$$
M_{\infty}=6, \operatorname{Re}_{\infty}=2.08 \times 10^{6} / \mathrm{ft}
$$
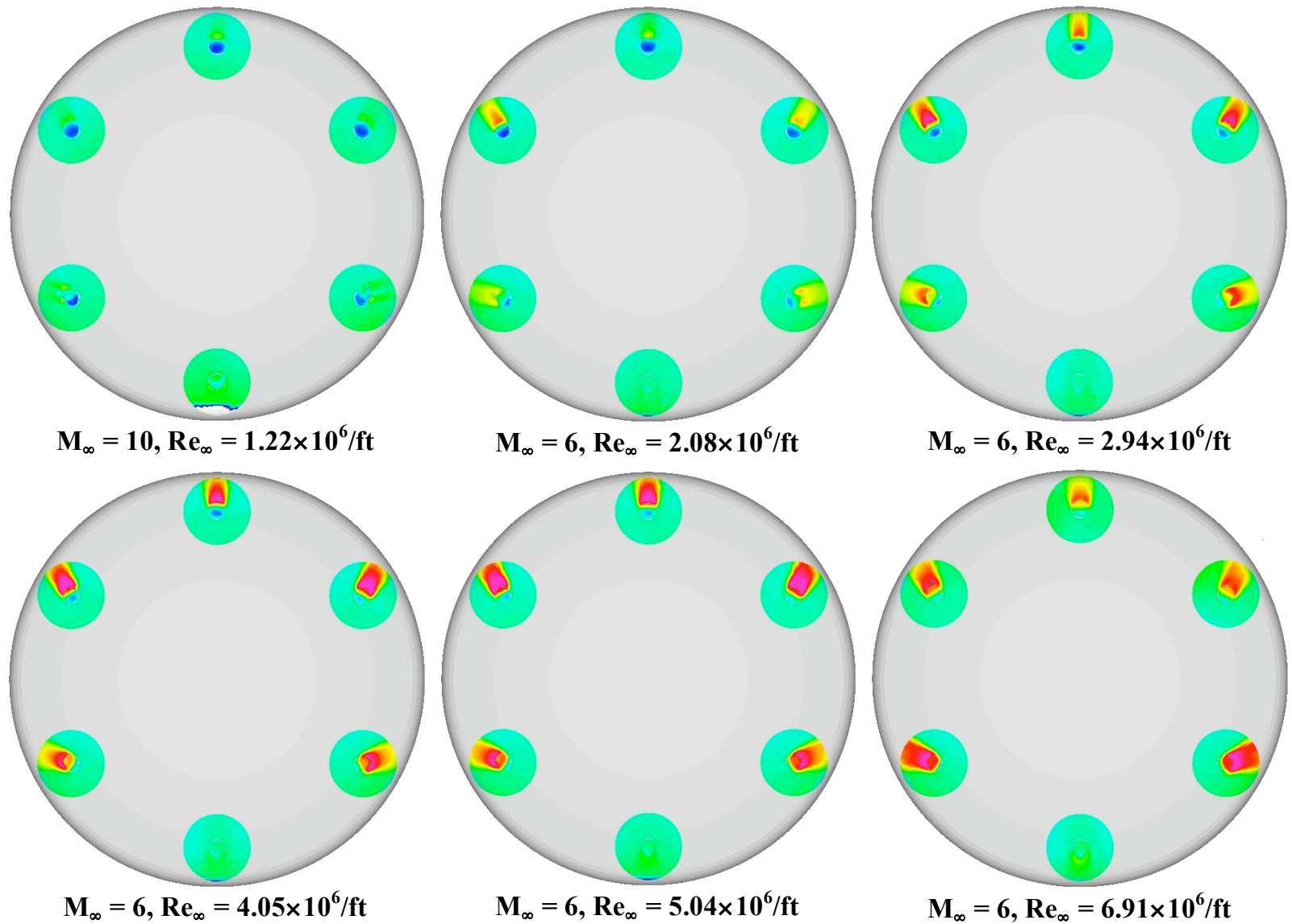

$M_{\infty}=6, \operatorname{Re}_{\infty}=2.94 \times 10^{6} / \mathrm{ft}$

$M_{\infty}=6, \operatorname{Re}_{\infty}=5.04 \times 10^{6} / \mathrm{ft}$

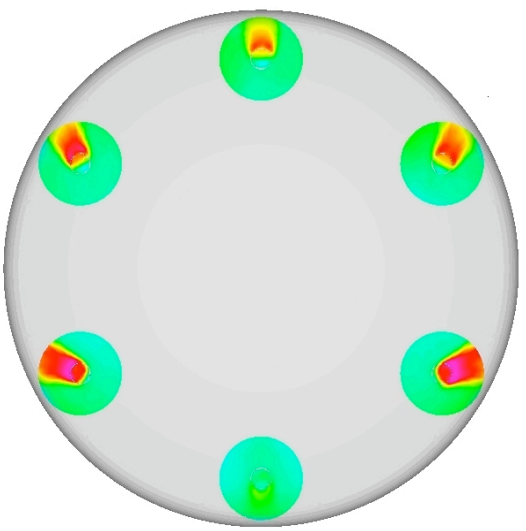

$M_{\infty}=6, \operatorname{Re}_{\infty}=6.91 \times 10^{6} / \mathrm{ft}$

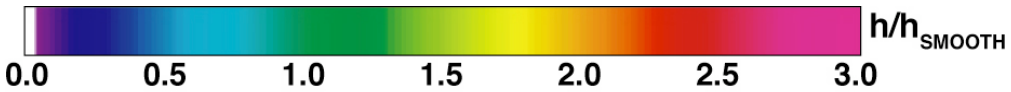

Figure 14. Heating augmentation factors around C1-D1 $\operatorname{model}$ pads, $\alpha=24$-deg 
The augmentation factors were $\sim 1$ around the pads, or $<1$ within the pads, for the lowest Reynolds numbers at which conditions the flow in and downstream of the pads remained laminar. For $\operatorname{Re}_{\infty} \geq 1.22 \times 10^{6} / \mathrm{ft}$, augmentation factors increased with Reynolds numbers to max values around 3 as the flow progressed from transitional to turbulent in and around the pads. Close examination of the augmentation factors around pads \#1, \#2, and \#6 (0-deg and \pm 60 -deg) shows that the augmentation factors actually decreased at the highest test Reynolds number of $\operatorname{Re}_{\infty}=$ $6.91 \times 10^{6} / \mathrm{ft}$. The decrease was due to the definition of the augmentation factor in this analysis, which is the measured pad heating relative to the measured upstream heating. At this highest Reynolds number, the flow upstream of these pads was already transitional and thus the measured reference values were higher than if the flow had remained laminar. So, although the actual dimensional heating was still the highest at this condition, the relative augmentation values were actually slightly lower than those of the next lowest Reynolds number conditions.

\section{Cavity Transition and Average Heating Augmentation Correlations}

1. Range of Cavity Average Heating Augmentation Data

Another parameter of interest to design of the CEV flight vehicle is the average heating augmentation over the surface top of each pad (i.e. the cavity floor), which is denoted as $\left(h / h_{\text {SмоотH }}\right)_{\text {AVG }}$. These values were determined for all pads and test conditions and the resulting values are plotted in terms of the boundary-layer momentum thickness Reynolds number, $\mathrm{Re}_{\theta}$, in Figure 15. These average augmentation factors varied from $\sim 0.5$ to $\sim 3.0$, however at first glance there seemed to be no correlation with $\mathrm{Re}_{\theta}$. Although not shown, a similar lack of correlation was found when the data were plotted against $\mathrm{Re}_{\theta} / \mathrm{M}_{\mathrm{e}}$. The maximum augmentation factors both on and downstream of the pad are also quantities of interest. Maximum values varied between 1 and 4, but the analysis of those data has not yet been completed.

More insight into the physics of this problem can be obtained when the data are color-coded with respect to the state of the boundary layer at and upstream of the compression pad cavities (Figure 16), as determined by examination of the data plotted and displayed as in Figure 12 to Figure 14. For conditions where the incoming flow was laminar and remained laminar downstream of the cavity, the average augmentation $\left(h / h_{\mathrm{SMOOTH}}\right)_{\mathrm{AVG}}$ decreased with $\mathrm{Re}_{\theta}$ to a minimum value of $\left(h / h_{\mathrm{SMOOTH}}\right)_{\mathrm{AVG}} \sim 0.4$. For cases where the cavity caused transition, average augmentation factors increased to a maximum of $\left(h / h_{\mathrm{SMOотH}}\right)_{\mathrm{AVG}} \sim 2.5$. And finally, for cases where the incoming flow was transitional or turbulent, the average augmentation factor decreased (as defined relative to measured upstream levels) from the 2.5 max value. Of particular interest in this plot is that the average augmentation factor at the pad approaches 1 at the highest Reynolds numbers, which indicates that for fully-turbulent incoming flow conditions, the average pad heating is no higher (approximately) than the incoming turbulent level.

These data clearly indicate that the cavity effects are a function of the boundary-layer state. Thus, in order to develop a correlation for the heating augmentation factors, a correlation must first be developed that can be used to define the onset of transition at a compression pad cavity.

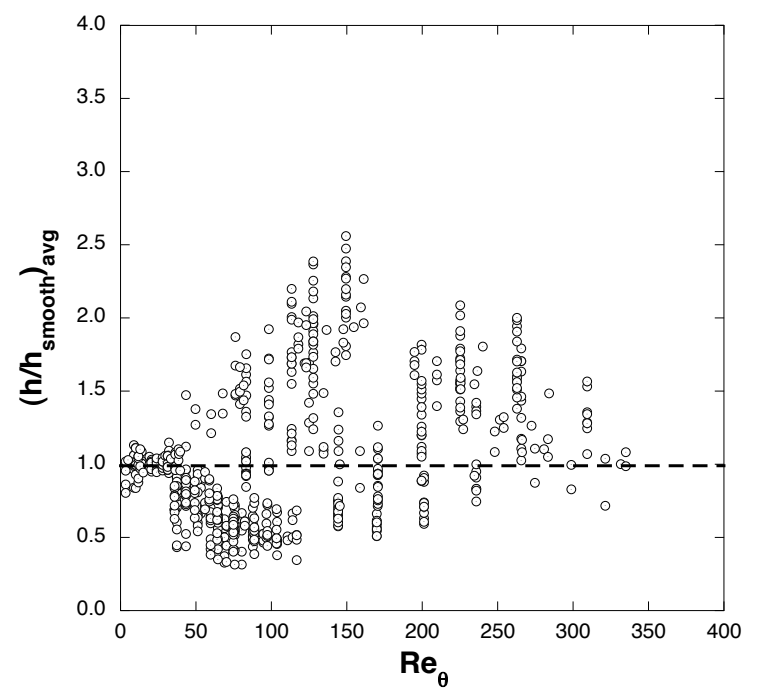

Figure 15. Average heating augmentation factors for all pads, all test conditions

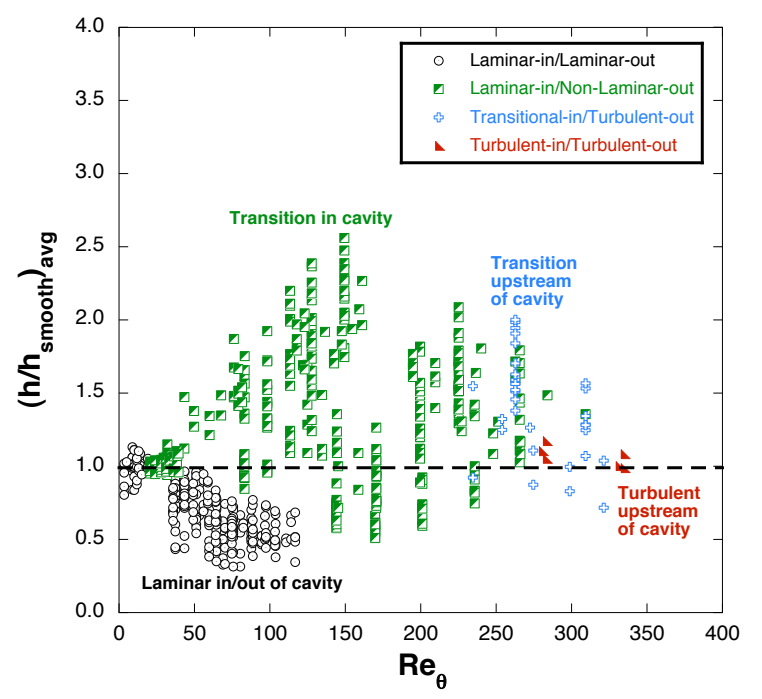

Figure 16. Average heating augmentation factors classified by boundary-layer state

11

American Institute of Aeronautics and Astronautics 


\section{CEV Closed-Cavity Transition Correlation}

A first attempt at correlating cavity-induced transition on the CEV was performed by applying transition criteria developed for cavities on the Mars Science Laboratory (MSL) heat-shield (Refs. 14 - 16). Although the carriervehicle attachment points were eventually eliminated from the MSL heat-shield by moving them to the aftbody of the vehicle, an extensive database was developed through wind tunnel testing and analysis that also included an earlier similar study for the Genesis mission (Ref. 17). This database was used to develop the correlations shown in Figure 17 for cavity size and flow conditions that bound fully-laminar and fully-turbulent flow produced at a cavity.

Transition onset values were determined from the current CEV data set, as well as from the data in Ref. 3, which provided smaller cavity aspect ratio data $(D / H=5$ to 10$)$ as well as data $(D / H=11$ to 18$)$ that overlap the current data set $(D / H=11$ to 45$)$. These values are compared to the MSL laminar/transitional boundary in Figure 18, which is comprised almost entirely of data points from cavities with aspect ratios in the $D / H=1$ to 4 range. Unfortunately, the only CEV data that come close to matching the MSL correlation are those for the $D / H=5$ to 6 data; the remaining CEV data clearly diverge farther from the MSL curve as a function of the cavity aspect ratio.

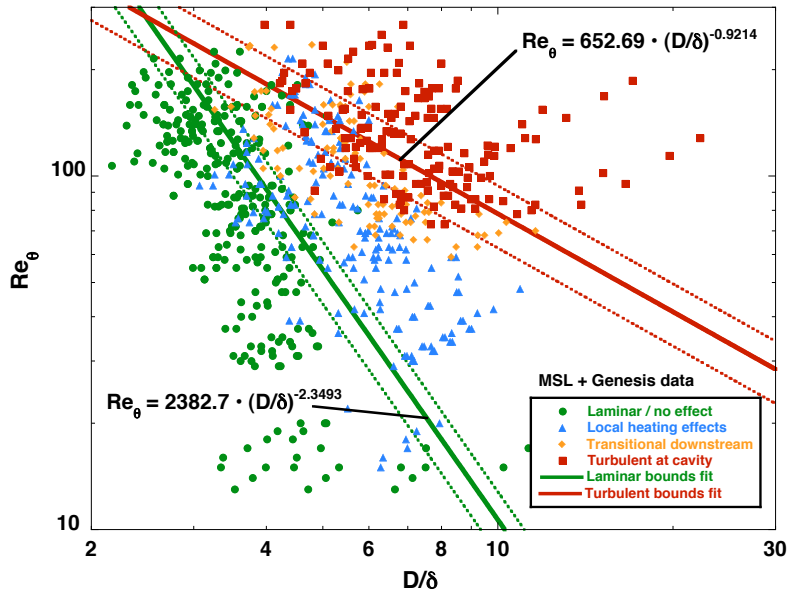

Figure 17. Laminar and turbulent boundaries from MSL transition study (Ref. 16)

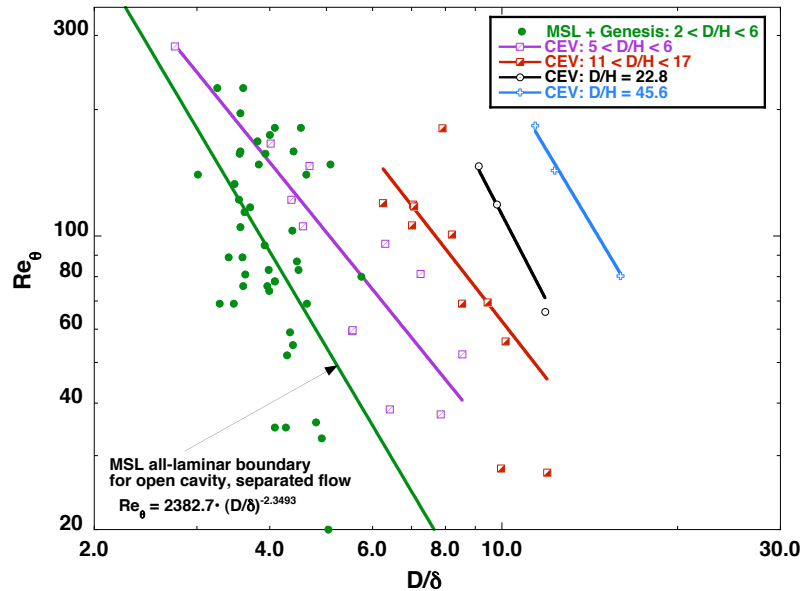

Figure 18. CEV transition-onset data compared to MSL laminar boundary criterion

The reason that the MSL correlation does not work for the CEV data is that because of the difference in sizes between the two sets of cavities, the CEV and MSL cavities flows represent different flow regimes. As shown in Figure 19 , a delineation is typically (e.g. Refs. 18,19$)$ made between small aspect ratio $(D / H<10)$ and large aspect ratio $(D / H>15)$ cavities. An open cavity (e.g. the MSL data) produces separated, recirculating flow with the cavity, whereas the flow attaches to the cavity floor in a closed cavity (e.g. the majority of the CEV data).

Following the definitions presented in Figure 19, the C0-D1 and C1-D1 models $(D / H=45.6$ and 22.8 , respectively) can clearly be expected to produce closed-cavity, attached flow, whereas the C3-D1 model $(D / H=5.7)$ should produce open-cavity, separated flow. The C1-D2 and C2-D1 models (both with $D / H=11.4$ ) fall into the intermediate cavity regime, but will provisionally be treated as closed-cavities. Additional CEV data from Ref. 3 span the range from open to closed cavity flow.

Open-cavity, separated flow $\mathrm{D} / \mathrm{H}<10$ (approx.)

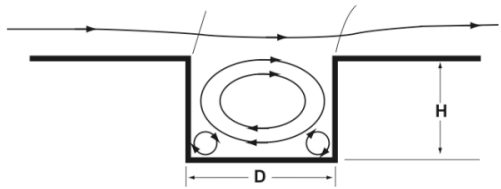

Intermediate cavity $10<\mathrm{D} / \mathrm{H}<15$ (approx.)

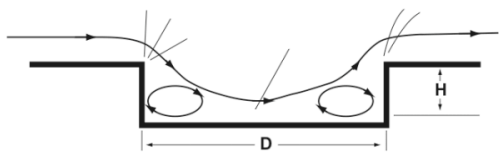

Closed-cavity, attached flow $15<\mathrm{D} / \mathrm{H}$ (approx.)

Figure 19. Illustration of open and closed cavity flow regimes

12

American Institute of Aeronautics and Astronautics 
With respect to the actual CEV flight vehicle, current designs call for very large aspect ratio (wide and shallow) cavity design. Thus, a transition correlation relevant to close-cavity, attached flow is required. Because the MSL methodology (in which transition was shown to correlate in terms of $\mathrm{Re}_{\theta}$ and the ratio of cavity diameter to boundary layer height, $D / \delta$ ) was shown to be invalid for $\mathrm{CEV}$, a different functional relationship was required. Since closed cavity flows produce attached flow on the cavity floor and then the cavity end-wall provides the flow field disturbance that causes transition, a analogy to transition correlations for discrete boundary-layer trips can be made. For such correlations (e.g. Ref. 20), boundary-layer transition is treated as a function of $\mathrm{Re}_{\theta} / \mathrm{M}_{\mathrm{e}}$ (rather than just $\mathrm{Re}_{\theta}$ ) and the ratio of trip height (or in this case cavity depth) to boundary-layer thickness, $\mathrm{H} / \delta$.

Such a correlation is presented in Figure 20 based on all CEV data for $11.5<D / H<45.6$. A good fit was produced with a correlation coefficient of 0.86 . The divergence of the open-cavity, separated flow CEV, MSL and Genesis data from this fit can also be seen. If the intermediate cavity data $(D / H=11.5)$, which are not relevant to current CEV designs are excluded, the correlation coefficient can be increased to 0.97 as shown in Figure 21. So, depending on the range and accuracy required, either of the following relations made be used to predict the onset of transition due to compression pad cavities for closed-cavity, attached flows.

$$
\begin{aligned}
& \frac{\operatorname{Re}_{\theta}}{M_{e}}=92.45 \times\left(\frac{H}{\delta}\right)^{-0.43999} \text { for }\left(\frac{D}{H}\right)>11.5 \\
& \frac{\operatorname{Re}_{\theta}}{M_{e}}=86.44 \times\left(\frac{H}{\delta}\right)^{-0.49685} \text { for }\left(\frac{D}{H}\right)>18
\end{aligned}
$$

Having developed a transition criteria, separate correlations for laminar-in/laminar-out and laminarin/transitional-or-turbulent-out average heating augmentation factors now can be developed. However, a few provisions on the applicability of all these correlation must first be provided. At the test conditions of this study, the edge Mach numbers on the blunt forebody of the CEV models ranged from $\mathrm{M}_{\mathrm{e}}=0.1$ to 1.1 ; thus there is little overlap between these data and data on flat-plates or lifting vehicles such as the Shuttle, X-33, or X-38 with edge Mach numbers ranging from $\sim 1$ to $\sim 4$. Also, these data were obtained in perfect-gas wind tunnel in which the parameters $\delta / \theta$ and $T_{w} / T_{e}$, which are sometimes employed in transition correlations, varied only slightly. Approximate relations for these parameters as a function of $\operatorname{Re}_{\theta}$ are provided in Figure 22 and Figure 23.

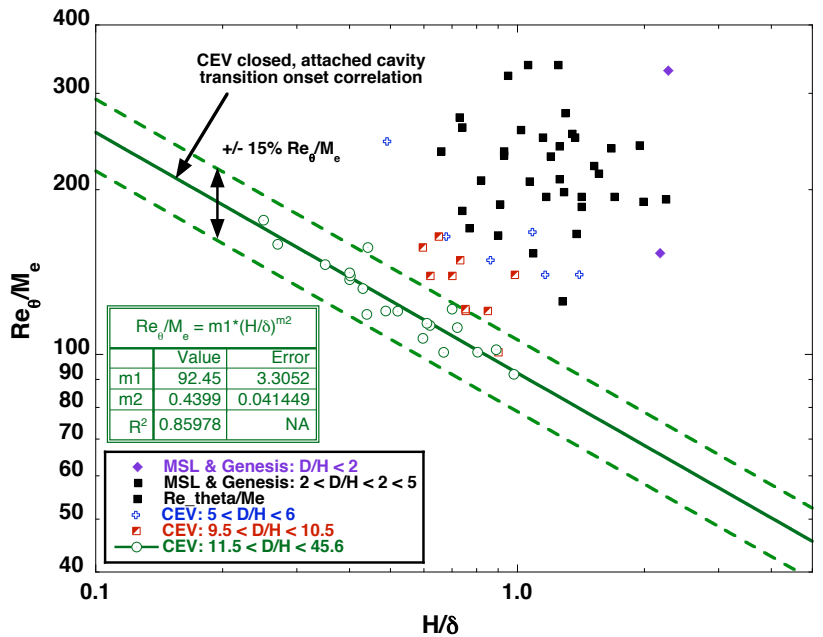

Figure 20. CEV transition criteria for closed-cavity, attached flow

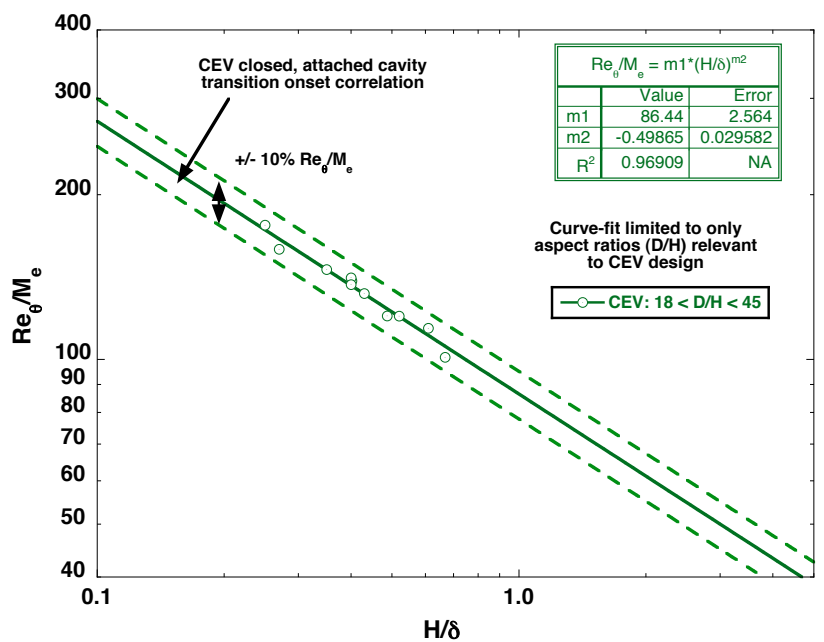

Figure 21. CEV closed-cavity, attached flow transition criteria refined to large $(\mathrm{D} / \mathrm{H})$ 


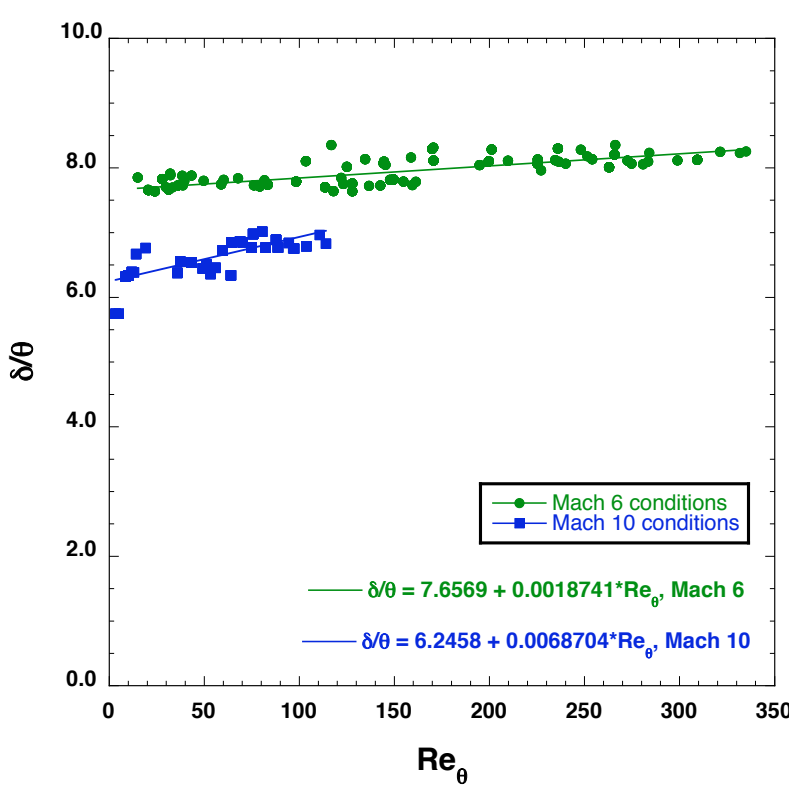

Figure 22. Approximate relation for variation of $\delta / \theta$ as a function of $\operatorname{Re}_{\theta}$ on the CEV models

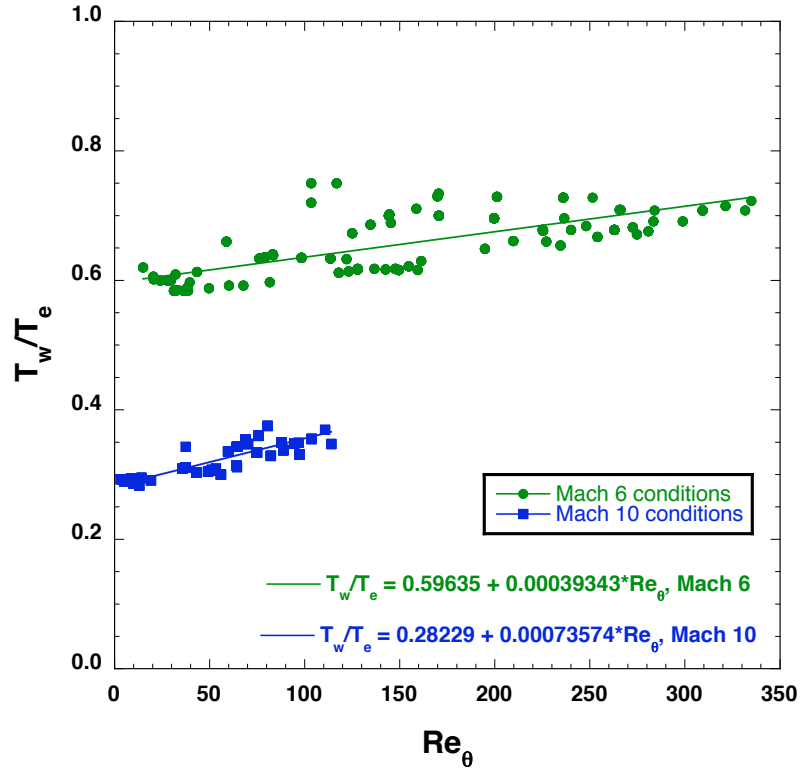

Figure 23. Approximate relation for variation of $T_{w} / T_{e}$ as a function of $\operatorname{Re}_{\theta}$ on the CEV models

\section{CEV Average Cavity Heating Augmentation Correlations}

The pad-averaged heating augmentation factor data that correspond to laminar-in / laminar-out conditions, as identified using the transition criteria of Eq. (1) or Eq. (2) are plotted in Figure 24 vs. $\operatorname{Re}_{\theta}$. These data were sorted by the cavity aspect ratio and showed a clear trend of increasing augmentation with increasing aspect ratio; or, looking at it from the other direction, the cavity floor became cooler as the cavity became deeper. Based on this trend, a correlation variable was defined by dividing $\mathrm{Re}_{\theta}$ by the cavity aspect ratio, as shown in Figure 25 . Plotted in this matter, the data showed a clear "s-curve" shape with augmentation factors that varied from a maximum of $\sim 1$ to a minimum of $\sim 0.3$. This behavior is similar to that of a hyperbolic tangent function, and so a correlation equation of that form was developed for these data. This laminar-in/laminar-out closed-closed cavity attached flow augmentation factor correlation is given by:

$$
\begin{aligned}
& Y=\left(1-\frac{1}{M 1}\right)-\left(\frac{1}{M 1}\right) \times \tanh \left[\frac{2.718(X-M 2)}{M 2}\right], M 1=4.0152, M 2=2.3589 \\
& \text { where } X=\operatorname{Re}_{\theta} \times\left(\frac{D}{H}\right)^{-1} \text { and } Y=\left(\frac{h}{h_{\text {SМоотH }}}\right)_{A V G}
\end{aligned}
$$

This function has a correlation coefficient of 0.787 and fits the majority of the C0-D1 and C1-D1 model cavity data $(D / H$ of 45.6 and 22.8 , respectively) to within $\pm 15 \%$ limits. The major divergences from this curve fit were from the C1-D2 and C2-D1 model data; these two models both had aspect ratios of $D / H=11.5$, which are between the open and closed cavity limits. There was also fair amount of scatter at the very low X values where the augmentation should ideally approach 1 . These data were mostly from pad \#4 which is in the stagnation region. These data were harder to optically acquire than elsewhere on the model because the stagnation region surface was more inclined away from the camera line-of-sight due to curvature of the model. Also, the boundary-layer variables extracted from the numerical computations are thought to be less well defined since the flow velocity approaches zero at the stagnation point. 


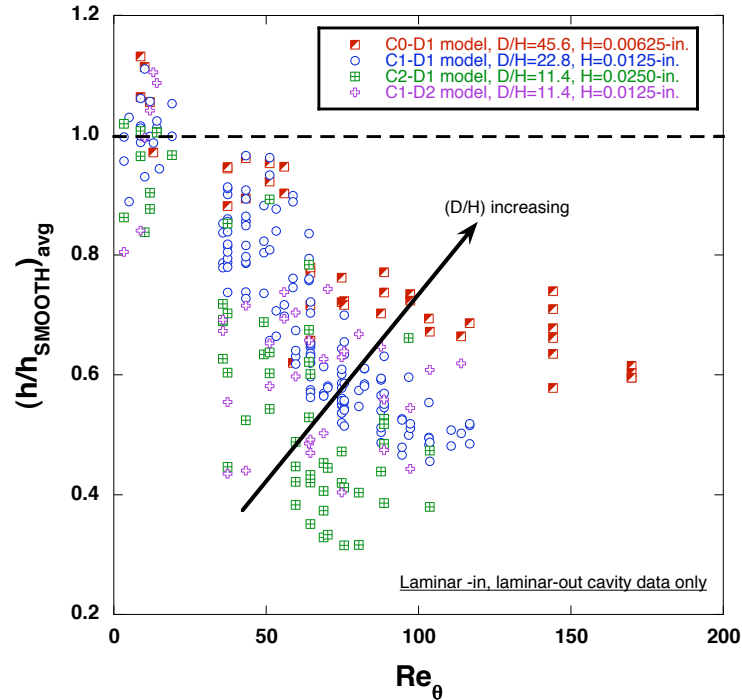

Figure 24. Laminar, closed-cavity, attached-flow augmentation factors vs. $\operatorname{Re}_{\theta}$

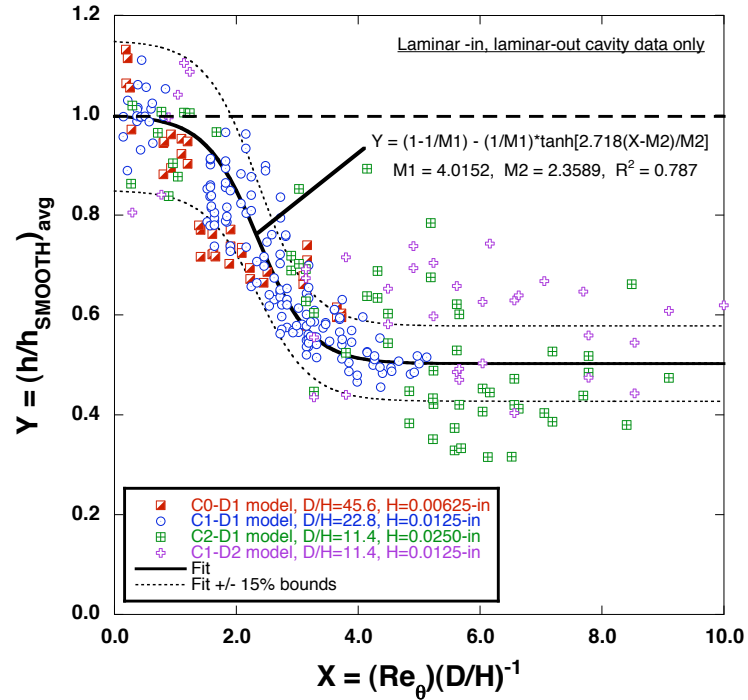

Figure 25. Correlation function for laminar, closedcavity, attached-flow augmentation factors

The laminar-in / transitional-or-turbulent-out heating augmentation factor data was found to require a different correlation function than the laminar-in / laminar-out data. A plot of these data is shown in Figure 26 in terms of $\operatorname{Re}_{\theta}$ with the values color-coded by pad aspect ratio. Three trends were evident from this plots: first, that the augmentation factors increased with $\mathrm{Re}_{\theta}$; second, that the augmentation factors increased with pad depth; and finally, that the data from each pad on a given model fell into separate regions.

To collapse these data, they were first plotted in terms of $\mathrm{Re}_{\theta} / \mathrm{M}_{\mathrm{e}}$, as shown in Figure 27; however considerable spread was still evident. Through a trial-and-error process, it was determined that plotting the data in terms of $\left(\operatorname{Re}_{\theta} / \mathrm{M}_{\mathrm{e}}\right)\left(1 / \mathrm{M}_{\mathrm{e}}\right)$ provided a much better collapse as shown in Figure 28, although a dependence on aspect ratio was still evident. Additional trial-and-error fitting led to the inclusion of the factor $(\mathrm{D} / \mathrm{H})^{-0.24}$ and a final correlation function of the form:

(4) where $X=\left(\frac{\operatorname{Re}_{\theta}}{M_{e}}\right)\left(\frac{1}{M_{e}}\right)^{1 / 2}\left(\frac{D}{H}\right)^{-0.24}$ and $Y=\left(\frac{h}{h_{\text {SМоотH }}}\right)_{\text {avg }}$

As with the laminar augmentation correlation, this function fits the majority of the high cavity aspect ratio data from the C0-D1 and C1-D1 models to within $\pm 15 \%$ limits. Greater differences were seen in the C2-D1 and C3-D1 model data, which have cavity aspect ratios of 11.5 and 5.7

4. CEV Open Cavity Correlations

At this point, no attempt has been made to develop transition or heating augmentation correlations that encompass both open and closed cavity data since open cavity flows are not likely to be experienced by the CEV vehicle. However, such correlations for blunt-body, subsonic boundary-layer flow may be possible (if more complex) and will be explored in the future. One such unified open and closed cavity correlation for supersonic boundary-layer edge flow has recently been developed for Shuttle Orbiter damage assessment (Refs. 21, 22).

5. Turbulent and Tripped Data Correlations

The correlations developed herein do not take into account data from the wind tunnel tests in which the flow entering the compression pad cavities was already turbulent, whether from natural boundary-layer transition or due to discrete trips placed upstream of the cavities. While these data will be examined, it was shown in Figure 16 that the augmentation factors (as defined relative to the actual, measured upstream heating) for such cases were actually lower than for cases with laminar incoming flow followed by transition produced by the cavity. 


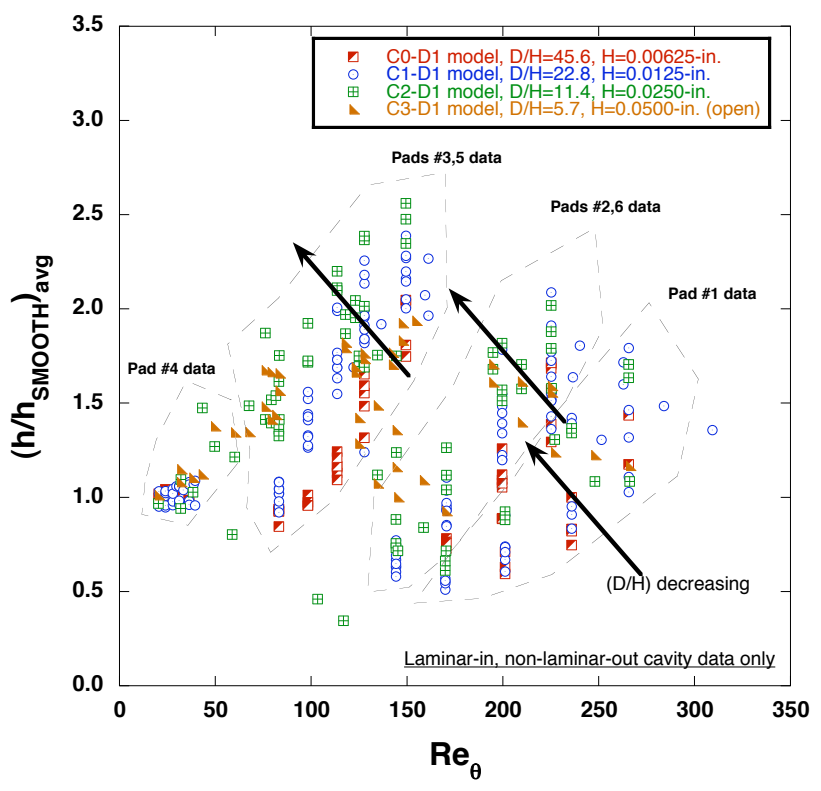

Figure 26. Transitional/turbulent, closed-cavity, attached-flow augmentation factors vs. $\mathbf{R e}_{\theta}$

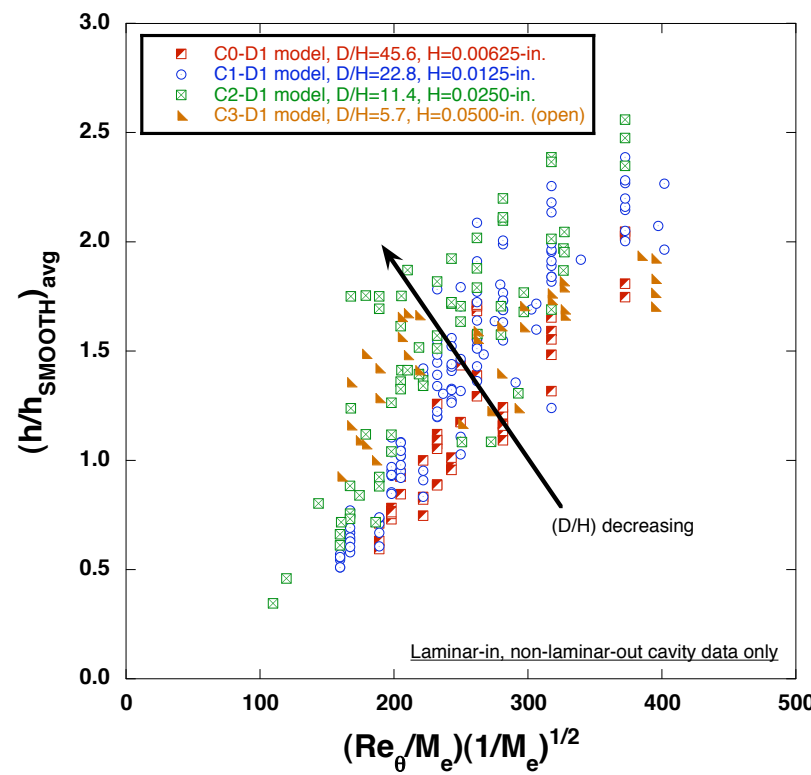

Figure 28. Transitional/turbulent, closed-cavity, attached-flow augmentation factors vs.

$$
\left(\operatorname{Re}_{\theta} / M_{e}\right)\left(1 / M_{e}\right)^{1 / 2}
$$

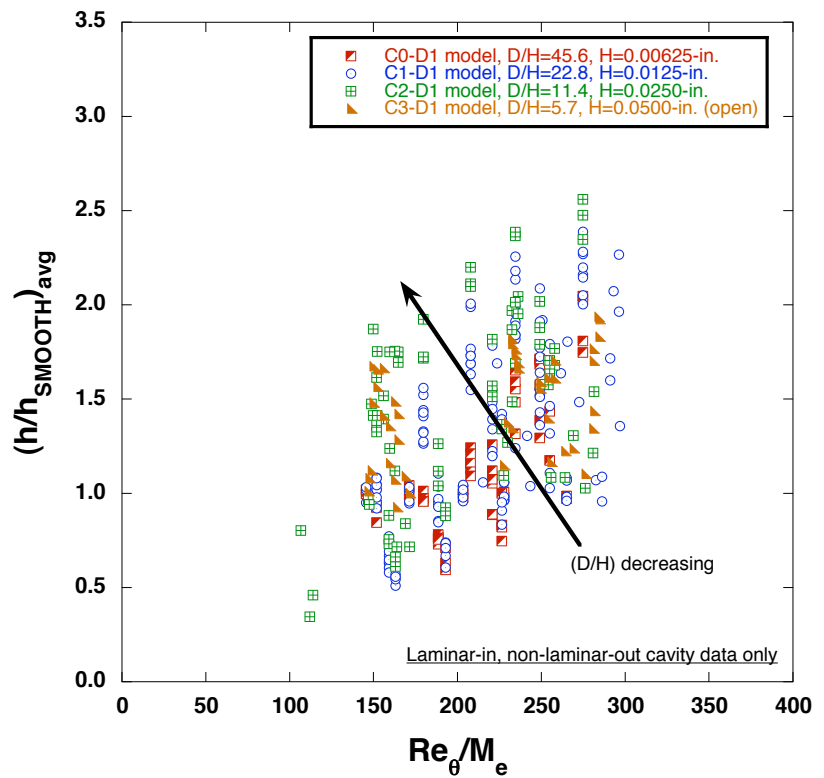

Figure 27. Transitional/turbulent, closed-cavity, attached-flow augmentation factors $v s . \operatorname{Re}_{\theta} / \mathbf{M}_{e}$

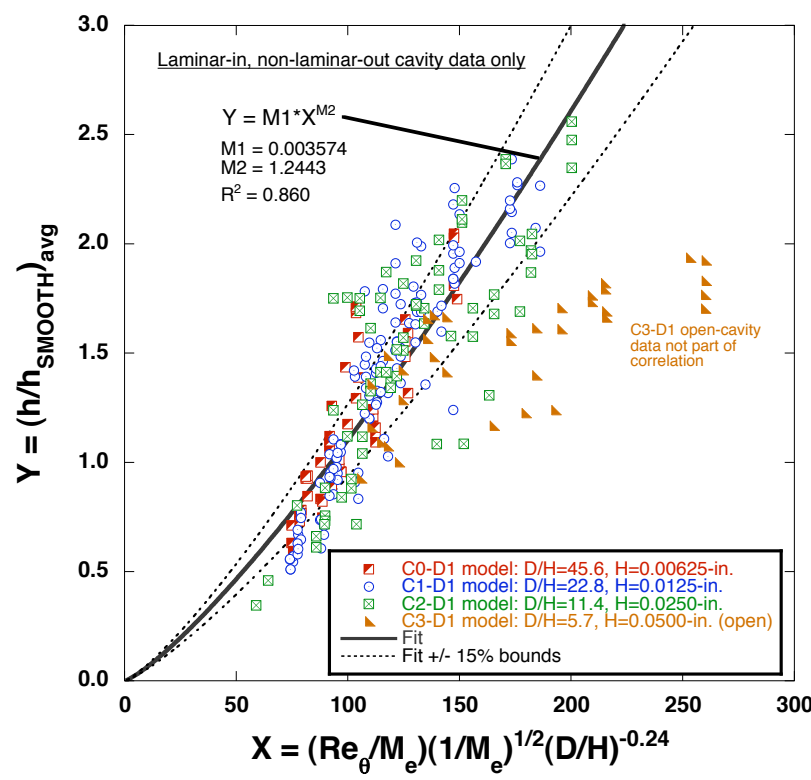

Figure 29. Correlation function for transitional/turbulent, closed-cavity, attached-flow augmentation factors 


\section{Summary and Conclusions}

The effects of recessed compression pads on the aeroheating environment of the CEV heat-shield have been studied through testing of a CEV models with various cavity dimensions at Mach 6 and Mach 10. Global heating data were obtained and mapped to three-dimensional surface geometries and detailed heating distributions were extracted from these maps along line-cuts through the center of each pad. Augmentation factors for the cavity effects on heating were determined by taking the ratio of measured heating at and around the pad to that measured on the smooth OML upstream of the pad.

The test conditions provided laminar incoming flow to all pads except for the three leeside pads at the highest test Reynolds number at Mach 6. Depending on pad geometry and local conditions, the boundary-layer state at and downstream of the pads varied from laminar to transitional to turbulent. Compression pad cavity floor-averaged augmentation factors varied from a minimum of approximately 0.3 at laminar-in / laminar-out conditions to a maximum of approximately 2.5 at laminar-in / turbulent-out conditions.

A cavity transition correlation was developed in terms of the boundary-layer parameter $R_{\theta} / M_{e}$ and the ratio of cavity depth to boundary layer height, $\mathrm{H} / \mathrm{\delta}$. This correlation is valid for closed-cavity, attached flow with cavity aspect ratios of $D / H>10$, which are applicable values to the design of the CEV vehicle. It was also shown that open-cavity, separated flow $(D / H<10)$ transition data do not fit this correlation; however such values are not within the $\mathrm{CEV}$ vehicle design space.

This transition correlation was used to classify the measured augmentation factors as either laminar or transitional/turbulent and separate correlation functions were developed for each data set. A majority of the closedcavity heating augmentation factor data fell with $\pm 15 \%$ of these correlation fits, while larger differences were evident in the open cavity data.

\section{References}

1 'NASA's Exploration Systems Architecture Study, Final Report,” NASA TM-2005-214062, November, 2005.

${ }^{2}$ Hollis, B. R., "Heating Augmentation in Laminar Flow Due to Heat-Shield Cavities on the Project Orion CEV," AIAA Paper 2008-6558, AIAA Atmospheric Flight Mechanics Conference and Exhibit, Honolulu, HI, August 18-21, 2008.

${ }^{3}$ Liechty, D. S., "Aerothermodynamic Testing of Protuberances and Penetrations on the NASA Crew Exploration Vehicle Shield," AIAA Paper 2008-1240, 46 ${ }^{\text {th }}$ AIAA Aerospace Sciences Meeting and Exhibit, Reno, NV, January 7-10, 2008.

${ }^{4}$ Buck, G. M., "Rapid Model Fabrication and Testing for Aerospace Vehicles," AIAA Paper 2000-0826, 38 ${ }^{\text {th }}$ AIAA Aerospace Sciences Meeting and Exhibit, Reno, NV, January 10-13, 2000.

${ }^{5}$ Micol, J. R. "Langley Aerothermodynamic Facilities Complex: Enhancements and Testing Capabilities," AIAA Paper 98-0147, $36^{\text {th }}$ AIAA Aerospace Sciences Meeting and Exhibit, Reno, NV, January 12-15, 1998.

${ }^{6}$ Buck, G. M., "Surface Temperature/Heat Transfer Measurement Using a Quantitative Phosphor Thermography System,” AIAA Paper 91-0064, January 1991.

${ }^{7}$ Merski, N. R., "Global Aeroheating Wind-Tunnel Measurements Using Improved Two-Color Phosphor Thermography Methods, Journal of Spacecraft and Rockets, Vol. 36, No. 2, pp. 160-170, March-April 1999.

${ }^{8}$ Fay, J. A., and Riddell, F. R., "Theory of Stagnation Point Heat Transfer in Dissociated Air," Journal of Aeronautical Sciences, Vol. 25, No. 2., pp. 73-85, February 1958.

${ }^{9}$ Gnoffo, P. A., “An Upwind-Biased, Point-Implicit Algorithm for Viscous, Compressible Perfect-Gas Flows,” NASA TP-2953, February 1990.

${ }^{10}$ Cheatwood, F. M., and Gnoffo, P. A., "User's Manual for the Langley Aerothermodynamic Upwind Relaxation Algorithm (LAURA)," NASA TM 4674, April, 1996.

${ }^{11}$ Hollis, B. R., Berger, K. T., Horvath, T. J., Coblish, J. J., Norris, J. D., Lillard, R. P., and Kirk, B. S., "Aeroheating Testing and Predictions for Project Orion CEV at Turbulent Conditions, “AIAA Paper 2008-1226, 46 ${ }^{\text {th }}$ AIAA Aerospace Sciences Meeting and Exhibit, Reno, NV, January 7-10, 2008.

${ }^{12}$ Hollis, B. R., Horvath, T. J., Berger, K. T., Lillard, R. P., Kirk, B. S., Coblish, J. J., and Norris, J. D., "Experimental Investigation of Project Orion Crew Exploration Vehicle Aeroheating in AEDC Tunnel 9, "NASA TP-2008-215547, December, 2008.

${ }^{13}$ Hollis, B. R., "Experimental Investigation of Project Orion Crew Exploration Vehicle Aeroheating: LaRC 20-Inch Mach 6 Air Tunnel Test 6931,”NASA TM-2009-215718, April 2009.

${ }^{14}$ Liechty, D. S., and Hollis, B. R., "Mars Science Laboratory Experimental Aerothermodynamics with Effects of Cavities and Control Surfaces," Journal of Spacecraft and Rockets, Vol. 43, No. 2, March-April 2006, pp. 340-353.

${ }^{15}$ Hollis, B. R. and Liechty, D. S., "Transition Due to Heat-Shield Cavities on a Mars Entry Vehicle," Journal of Spacecraft and Rockets, Vol. 43, No. 2, March-April 2006, pp. 354-366. 
${ }^{16}$ Hollis, B. R., and Liechty, D. S., "Correlations for Boundary-Layer Transition on Mars Science Laboratory Entry Vehicle Due to Heat-Shield Cavities, NASA TP-2008-215317, June 2008.

${ }^{17}$ Cheatwood, F. M., Merski, N. R., Riley, C. J., and Mitcheltree, R. A., "Aerothermodynamic Environment Definition for the Genesis Sample Return Capsule," AIAA Paper 2001-2889, 35 ${ }^{\text {th }}$ AIAA Thermophysics Conference, Anaheim, CA, June 11-14, 2001.

${ }^{18}$ Charwat, A. F., Roos, J. N., Dewy, C. F., and Hitz, J. A., “An Investigation of Separated Flow - Part I, The Pressure Field,” Journal of the Aerospace Sciences, Vol. 28, No. 6, June 1961, pp. 457-470.

${ }^{19}$ Charwat, A. F., Dewey, C. F., Roos, J. N., and Hitz, J. A., "An Investigation of Separated Flow - Part I, Flow in the Cavity and Heat Transfer," Journal of the Aerospace Sciences, Vol. 28, No. 7, July 1961, pp. 513-527.

${ }^{20}$ Berry, S. A., and Horvath, T. J., "Discrete Roughness Transition for Hypersonic Flight Vehicles," Journal of Spacecraft and Rockets, Vol. 45, No. 2, March-April 2008, pp. 21-227.

${ }^{21}$ Everhart, J. L., "Supersonic/Hypersonic Laminar Heating Correlations for Rectangular and Impact-Induced Open and Closed Cavities," AIAA Paper 2008-1283, $46^{\text {th }}$ AIAA Aerospace Sciences Meeting and Exhibit, Reno, NV, January 7-10, 2008.

${ }^{22}$ Everhart, J. L., "Turbulent Supersonic/Hypersonic Heating Correlations for Open and Closed Cavities," AIAA Paper 2009$1400,47^{\text {th }}$ AIAA Aerospace Sciences Meeting, Orlando, FL, January 5-8, 2009. 